\title{
Sidney Kimmel
}

\section{Cancer Center}

Jefferson Health.

$\mathrm{NCl}$ - designated

\section{Gibbon Surgical Review}

Volume 1, Issue 2, November 2018

Prepared for: The 13th Annual Pancreatic Cancer

and Related Diseases Patient Symposium

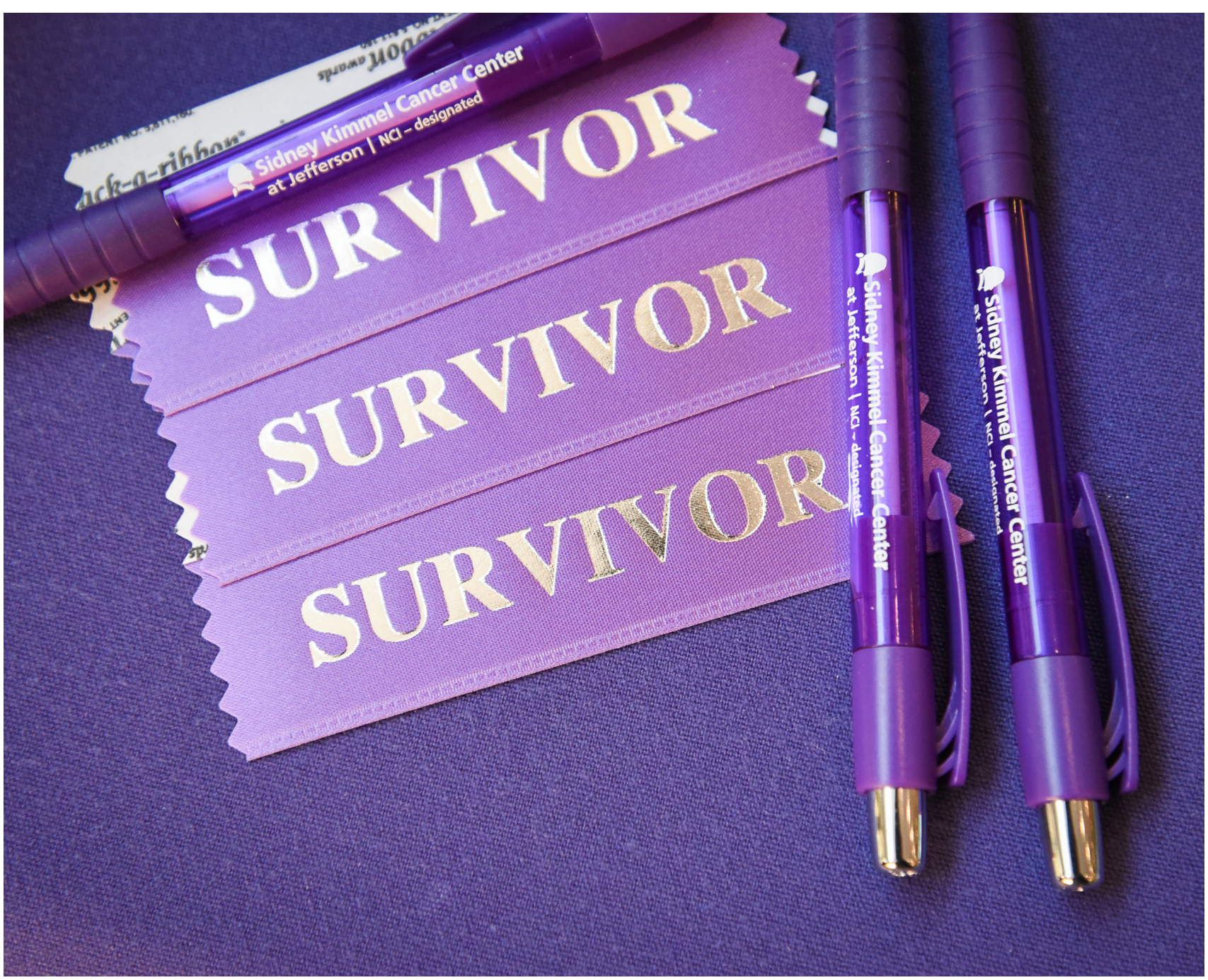




\section{Table of Contents}

03 Forward by Charles J. Yeo, MD, FACS

05 PERSPECTIVE

An Interview with Dr. Theresa

Yeo, Co-Director of the

Jefferson Pancreas Tumor

Registry (JPTR)

10 A PGY-1's Perspective:

Conducting Pancreatic Cancer

Research as a Medical Student

12 INTERVIEW

Jonathan Brody, PhD Pancreatic Cancer Specialist

17 RESEARCH SPOTLIGHT

The Journal of Pancreatic Cancer

19 Pancreatic Cancer Research at Jefferson: The Mary Halinski Pancreatic Cancer Research Fund

24 The Gibbon Surgical Society

26 Contributors

27 Samuel D. Gross Professor of Surgery: Charles J. Yeo, MD, FACS

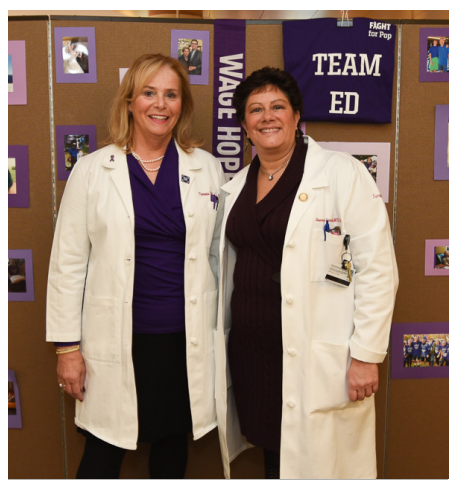

The Co-Director of the Jefferson Pancreas Tumor Registry sits down with a third-year medical student and answers questions regarding her research, the role of clinical nurse specialists, and going back to school to get her PhD.
Dr. Brody meets with a third-year medical student to talk about his track to becoming a PhD and where he sees pancreatic cancer treatment and research going in the upcoming years.

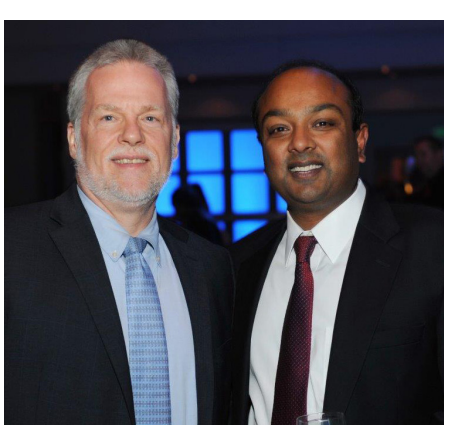

Bob Halinski, founder of the Mary Halinski Pancreatic Cancer Research Fund and recipient of the 2018 Community Impact Award, and Dr. Harish Lavu sit down with a second-year medical student to discuss the Halinski Fund and the state of pancreatic cancer research. 


\section{Hello and Welcome}

It is with great delight that I welcome you to this, our 13th Annual Pancreatic Cancer and Related Diseases Patient Symposium. This is our most special event of the year. It is with much anticipation that we plan this event. We welcome back many of our patients, friends, and families. We also welcome those who are new to Jefferson, and to this symposium.

I hope that you enjoy the contents of this extensive publication, which has been supervised by our superb Sidney Kimmel Medical College of Thomas Jefferson University medical students, some of whom may be pancreas surgeons some day!

In this publication you will find some fascinating stories, interviews, research updates, and contributions. We are proud to be leaders in the field of pancreatic and related cancer research, not only clinical research but bench research, translational research, and epidemiological research. We hope that you find this day exciting, invigorating, educational, and tasty (we do provide free breakfast and lunch).

Thank you for celebrating Pancreatic Cancer Awareness Month with us, and for joining us here at Jefferson as we continue to make an impact in our fields of research and clinical care delivery. There are many exciting things going on here at Jefferson Health. It is terrific to see you join us in the fight.

Yours sincerely,
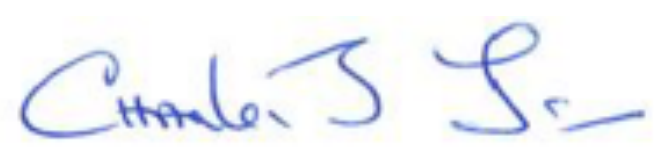

Charles J. Yeo, MD, FACS

Samuel D. Gross Professor and Chairman

Department of Surgery

Senior Vice President and Chair, Enterprise Surgery

Jefferson Health 

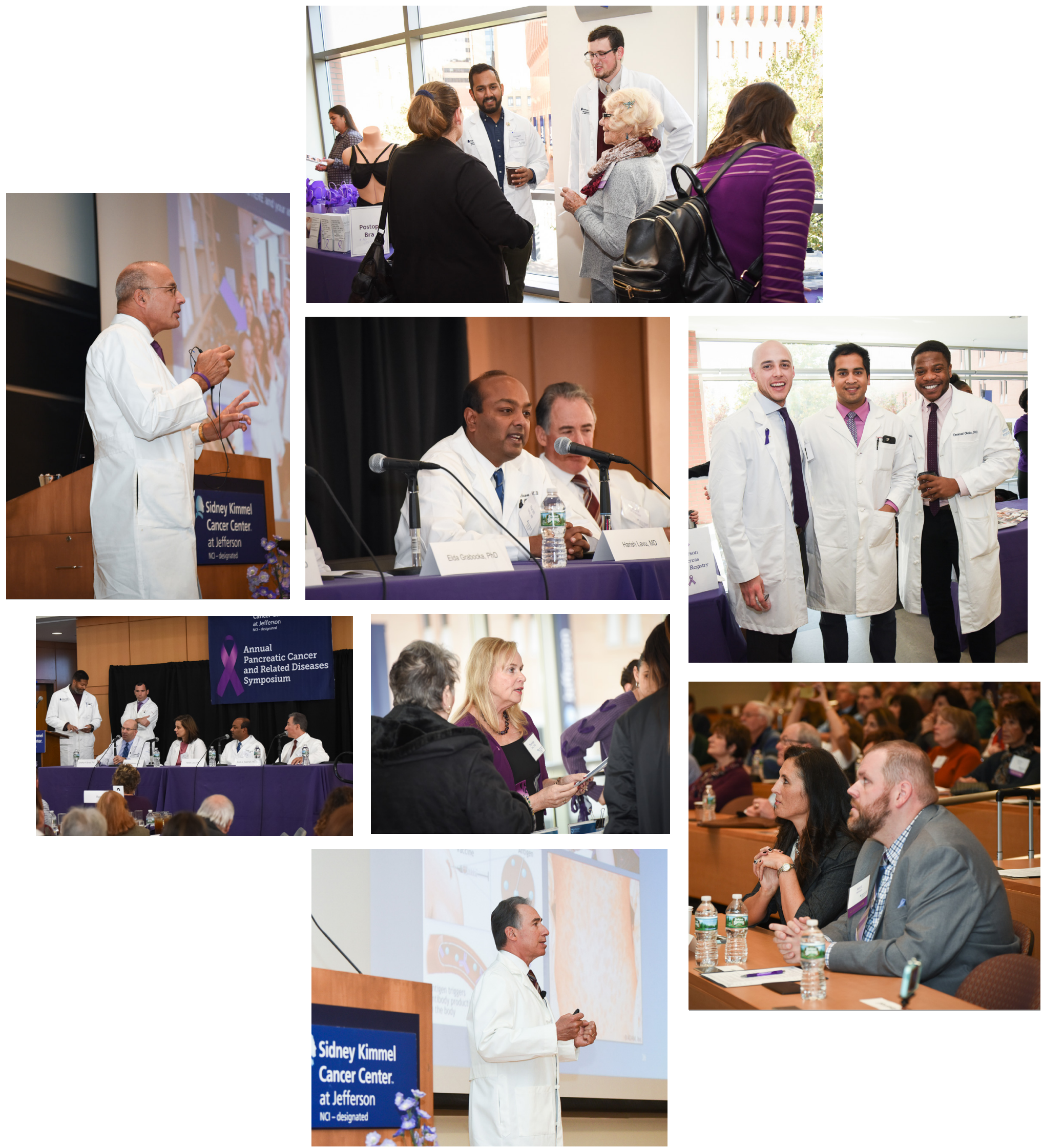


\title{
PERSPECTIVE
}

\section{An Interview with Dr. Theresa Yeo, Co-Director of the Jefferson Pancreas Tumor Registry (JPTR)}

\author{
BY: NICHOLAS SIENA, CLASS OF 2020
}

Dr. Theresa Yeo received her BSN from Cornell University in 1976, an MSN from the University of Virginia, and MPH and PhD degrees in public health from the Johns Hopkins University, Bloomberg School of Public Health.

She spent 30 years of her career in Baltimore, MD, as a Johns Hopkins nurse, Johns Hopkins School of Nursing faculty member, and researcher before coming to Jefferson with her husband, Dr. Charles J. Yeo, Samuel D. Gross Professor of Surgery.

\begin{abstract}
Since her 2005 arrival in Philadelphia, she has served as an Associate Professor in the Jefferson College of Nursing, Program Director for Oncology Nursing, Co-Director of the Jefferson Pancreas Tumor Registry, and a nurse practitioner in the Jefferson Pancreas, Biliary and Related Cancer Center. Dr. Theresa Yeo continues to teach nursing and medical students, mentor doctoral level students, conduct investigator-initiated research focused on symptom management and quality of life issues in cancer patients, and publish and disseminate research findings at national and international symposia. She has received federal, societal, intramural, and private research funding.

Dr. Yeo has published 53 peer-reviewed articles and abstracts and 16 book chapters, and co-edited one cookbook. She is an Associate Editor of the Journal of Pancreatic Cancer and serves on numerous peer-review editorial boards, including Annals of Surgery, JOGS, CJON, the Journal for Nurse Practitioners, Oncology Nursing Form, and the Journal of Allied Health. She was an expert reviewer for the 2018 Kaiser Permanente Research Affiliates Evidence-based Practice Center Project: "Screening for Pancreatic Cancer: A Systematic Evidence Review for the U.S. Preventive Services Task Force" (Prepared for the Agency for Healthcare Research and Quality).
\end{abstract}

In 2017, she received the Distinguished Alumni Award from Cornell University in recognition of her contributions to the field of professional nursing.

\section{CONCERNING RESEARCH IN GENERAL}

Q: Was it always your intent to become a researcher or did something along the way inspire you to change course?

A: It was really just the next step. I was on the faculty at the Johns Hopkins School of Nursing and the Dean at that time was Martha Hill who encouraged the faculty to pursue advanced degrees. I chose a $\mathrm{PhD}$ in public health, as I was particularly interested in cancer, and the epidemiology of cancer. I was able to complete my education at the Johns Hopkins Bloomberg School of Public Health while a faculty member and the mother of two small children.

Q: You've written a paper about mentorship and mentors. Can you describe your most influential mentors?

A: One of my most important mentors has been my husband, Dr. Charles Yeo, who has encouraged me all along the way and even tutored me in biostatistics. I could not have completed a dissertation without his support and that of our family. Charlie's work with pancreas cancer patients was very interesting to me, and led me to get involved in the clinical care of pancreatic cancer patients and research in the area.

Q: What qualities did your mentors have that helped you grow in your career?

A: Being supportive. Letting you know that it wasn't necessarily about how smart you are, but how hard you were willing to work and persevere in what you want. I also had a great mentor in the Hopkins School of Nursing, Dr. Candis Morrison, who was a $\mathrm{PhD}$-prepared oncology nurse practitioner. We worked together on the hematologic malignancy service and she had a "you can do this" attitude that really helped me believe in myself.

\section{Q: Do you have advice for identifying a good mentor?}

A: It's really important for young people to have a mentor that they like and one in whose work they're interested. We all have informal mentors in our lives, but the professional ones should be formalized and that means having ground rules. It should be clear what is expected on both sides 
of that equation. A mentor has responsibilities and duties and the mentee has obligations and duties as well. Sometimes you have to try out a few mentors before you find the one that is going to work.

\section{CONCERNING PANCREATIC CANCER}

\section{Q: What drew you to pancreatic cancer research} specifically?

A: My husband's career! In the early 1990s the Johns Hopkins Department of Surgery applied for and received the first NIH SPORE grant to study pancreas cancer with Dr. Charles Yeo as the Principal Investigator. This stimulated a great deal of research in many related areas. At that time I was involved with the Hopkins National Familial Tumor Registry and I was able to use that database to develop a dissertation thesis, which evaluated environmental and occupational risk factors for pancreas cancer in a cohort of familial and sporadic pancreas cancer patients.

Q: What are the goals of the Jefferson Pancreatic Tumor Registry and what need did it fill that was previously unmet?

A: In 2005, when Dr. Yeo and I came to TJUH, there was not a pancreas tumor registry. We formed an Advisory Board and in 2008 the IRB approved the protocol for the JPTR and we began enrolling patients. Dr. Harish Lavu had recently arrived on the faculty from Indiana University and UCLA and served as the first Director of the Registry. Just this summer we published a descriptive review of the first 10 years of the Registry in the Journal of Pancreatic Cancer. ${ }^{1}$ The purpose of the Registry, a longitudinal, epidemiological study, is to collect information on hereditary conditions, family history of cancers, and occupations and environmental exposures to known human carcinogens. In conjunction with our Jefferson tumor-banking study, we are also able to use DNA tumor samples and family history to make decisions about personalized and precision therapy. Lastly, we sought to start a high-risk, nonaffected family member surveillance screening program. Through our annual follow-up surveys, a community of survivors and their relatives has been created. It is precious data and we recognize what a privilege it is to collect these data that describe the lived experience of people with pancreas cancer and other related conditions.

\footnotetext{
Q: Have there been any surprising findings so far?
}

A: There has been much interesting scientific research from the lab of Dr. Jonathan Brody, Director of Research in the Department of Surgery. For example, we have found polymorphisms in a tumor suppressor gene called WEE1 - SNP indels in an RNA binding site. Individuals who carry one specific allele enrichment pattern are more likely to have first-degree relatives with Lynch-type cancers.

Q: Is there anything being worked on now in the field that may dramatically change the detection or treatment of the disease in the near future?

A: The major treatment advances are going to be made on the molecular side. Finding out the molecular mutations and alterations in these various tumors and developing chemotherapies that can target those actionable mutations. Early detection is critical. We encourage all persons with a family history of pancreas cancer to be under surveillance by an experienced Gl physician who is familiar with pancreas cancer.

\section{CONCERNING YOUR RESEARCH INTERESTS}

Q: Could you describe some of your efforts regarding quality of life in patients with cancer?

A: This has been an interest of mine for a number of years. When you work with a cancer population with high rates of morbidity and mortality you think about their quality of life and what interventions may improve it. In 2009, we conducted a randomizedcontrolled trial in post-operative individuals with pancreas cancer using a home walking program as the intervention. We randomized post-Whipple patients to either the home walking program or to "usual care", meaning that they could perform any activity that they wanted. We assessed fatigue (the number one presenting symptom of pancreas cancer and also the most persistent symptom after treatment). Published literature suggested that walking and exercising helped decrease the symptom burden in cancer patients and we wanted to test that theory. We designed and carried out the study from 2009 to 2011. One hundred and one patients participated. We found that the group that walked and/or exercised had less fatigue, weight loss, anxiety, and depression. ${ }^{2}$ Based on those findings, we now routinely give our post-surgery patients a walking prescription to follow at home.

Q: What has motivated you to devote time to researching topics like exercise and relaxation in 


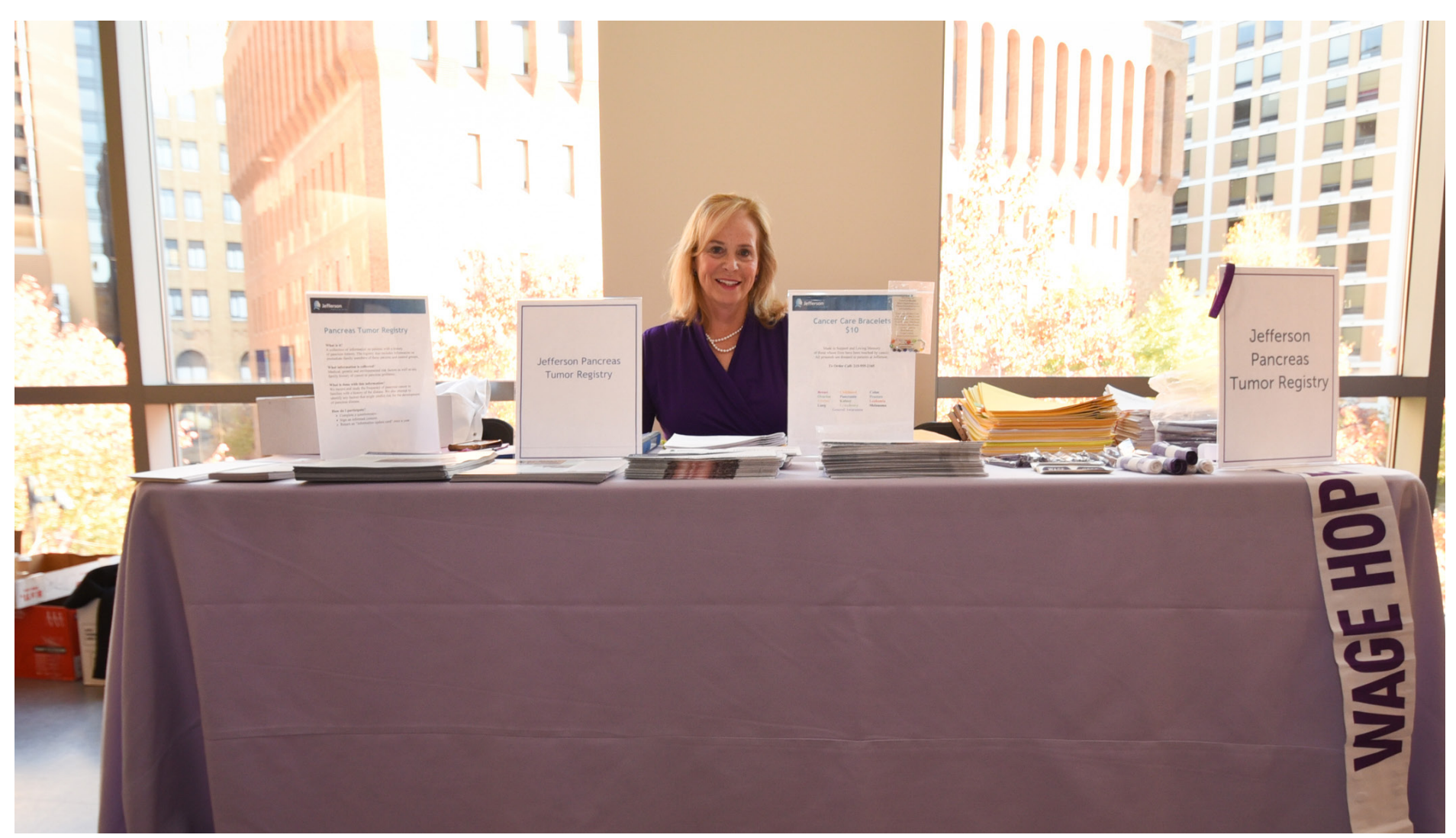

Dr. Theresa Yeo hosting the Jefferson Pancreas Tumor Registry information table at the 2016 Pancreatic Cancer and Related Diseases Patient Symposium

the cancer patient population?

A: There is such a need for this type of research. Cancer patients deal with difficult situations and multiple issues. You think to yourself: "What can I do as a healthcare professional to find ways to help people?" Exercise has been important in my life for dealing with stress and improving my own quality of life. We have a very motivated team of surgeons, oncologists, nurses, and nurse practitioners who are interested in helping change lives and conducting research.

Q: What research project do you look back and feel most proud of?

A: I was very proud of designing and completing my dissertation study. The walking study was also a well-done study. It was an amazing experience to connect with the patients, to talk with them every month and to read in their log sheets how they were doing and what problems they were having. I think it really helped people.

\section{CONCERNING NURSING}

Q: Has your background in nursing helped you in

\section{your career in research?}

A: Absolutely. I am first and foremost a nurse. I went to the Cornell University School of Nursing. It was an incredible, exceptional school. The nursing education that I received has held me in great stead for all of my career. In everything I do now, I'm still a nurse at heart.

Q: Is there anything you miss about clinical nursing that you don't get from your current position?

A: My current position is the perfect blend of being a clinical nurse practitioner and a researcher. I see patients in office hours, at the Jefferson Pancreas, Biliary and Related Cancer Center as part of our team every week. It is my favorite part of the position!

Q: The United States is projected to face an increasing shortage of physicians in the coming years. You've written that you think this is an area in which nurse practitioners (NPs) can play a larger role. Do you think that the medical profession will welcome a growing parity amongst physicians 


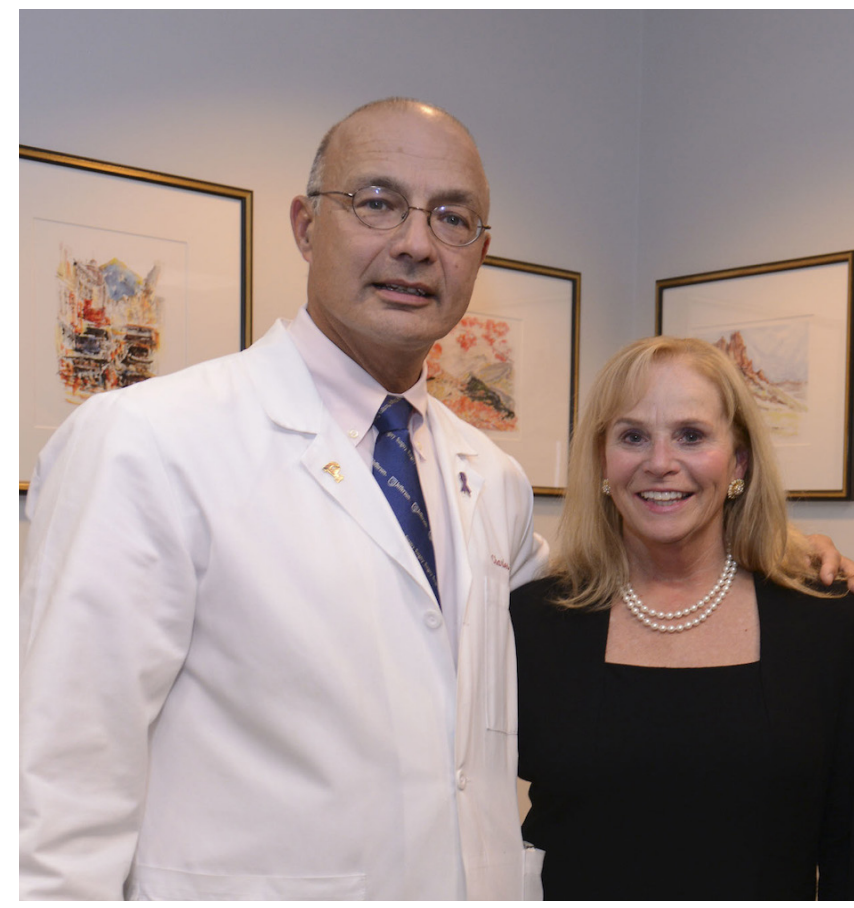

Drs. Charles and Theresa Yeo

and NPs, or do you think there will be resistance?

A: The role of the nurse practitioner can be both complementary to medicine and can be integrated into medicine. In my own career, I've always felt welcomed and valued as part of the team. I think that nurse practitioners can definitely play a larger role in health care, particularly in areas of need, such as rural areas where there are very few physicians. Physician Assistants have a growing role in this area as well. There is some resistance from the AMA, to nurse practitioners, but there are plenty of patients and areas in desperate need of health care providers to go around.

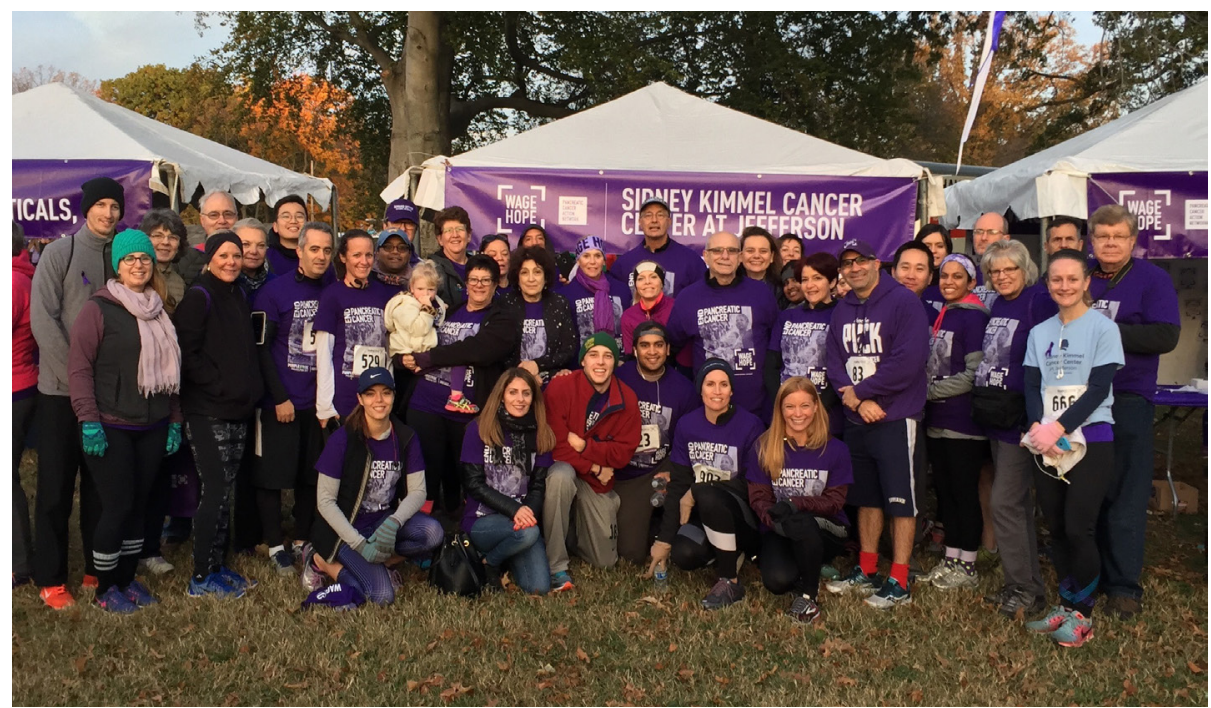

Q: Outside of increasing the role of NPs in primary care, what are the other areas of clinical medicine that you think would benefit from an increased presence of NPs?

A: There is a role for nurse practitioners in both inpatient and outpatient settings. Just about any setting is improved by having a nurse practitioner as part of the staff! The key to being a successful nurse practitioner, I would say, is to know when to ask for help, know what you don't know, and never pretend to know something you don't.

Q: You've written about the role of advanced practice nurses in culturally competent care in the field of oncology. Can you discuss that role and why advanced practice nurses are uniquely suited to overcoming or bridging cultural boundaries?

A: The demographics and cultural backgrounds of our society are changing. We need a workforce that can relate to people from many different backgrounds. Cancer is a much feared disease and a time when patients and their loved ones are facing some of the most difficult decisions of their lives. Having a health care provider who is culturally aware and sensitive is much appreciated by patients. Jefferson had one of the only programs in the country that was focused on preparing culturally competent advance practice nurses.

Q: What strategies do you think could foster a greater respect between physicians and NPs?

A: Many schools have started interdisciplinary programs in which nursing, pharmacy, physical therapy, and medical students work together on joint projects. I've been involved with some of these projects here at Jefferson as a faculty member. Students often know very little about each other's
Team Jefferson poses for a picture before the annual Pancreatic Cancer Action Network PurpleStride 5K 
role on the health care team, how their roles overlap, and how they could collaborate. I see that there is a growing awareness and acceptance of other peoples' roles and a greater collegiality as a result of these initiatives.

Q: You've looked into incivility in the healthcare work place. What tactics do you think can cut down on instances of incivility?

A: Incivility is a growing problem in our society. Each person has to take responsibility for their own behavior. There are a number of very simple tactics that can be used: count to ten before speaking, walk away from a difficult email and think it through before answering, listen more, talk less, and be respectful of others' opinions. When you have a problem, rather than letting it escalate, go and speak privately with whomever you are having the problem. Consider: "Is this their problem or is this my problem?" Ask yourself, "Who can I really change?" You can only change yourself. And that goes back to taking responsibility for your behavior and being more responsible about how you act in the workplace.

Q: How have you personally dealt with uncivil behavior both as a nurse and as a research scientist?

A: First let me say I've been both the perpetrator of incivility and the object of incivility. No one is perfect. Remember that you are a professional. Sometimes it requires you to walk away for a while, to sleep on it, and to not push the "send" button. One of the lessons I have learned in my career is to not overreact; not every perceived or real slight needs to be addressed. Choose your battles carefully and try to be rational, calm, and diplomatic in your approach.

\section{CONCERNING COOKING}

\section{Q: Your name is on a cookbook of Philadelphia's favorite recipes. Do you like to cook?}

A: I was honored to be president of the Jefferson Women's Board for three years. When I was president, the major project we undertook for fundraising was to compile a cookbook about Philadelphia cuisine. The cookbook featured Jefferson medical history and Philadelphia's culinary past. All of the recipes were submitted by members of the Jefferson community and they were all tested. My family tasted many of these recipes! It was a successful project and great fun.

\section{REFERENCES}

1. Yeo TP, Lavu H, Nevler A, et al. Precious Data: Interim Report from the Jefferson Pancreas Tumor Registry. Journal of Pancreatic Cancer. 2018;4(1):17-24. doi:10.1089/pancan.2018.0004

2. Yeo TP, Burrell SA, Sauter PK, et al. A progressive postresection walking program significantly improves fatigue and health-related quality of life in pancreas and periampullary cancer patients. J Am Coll Surg. 2012;214(4):463-475; discussion 475-477. doi:10.1016/j. jamcollsurg.2011.12.017
Bob Halinski and his daughter, Stephanie Kensy, stand at the 2017 Ride and Renew event

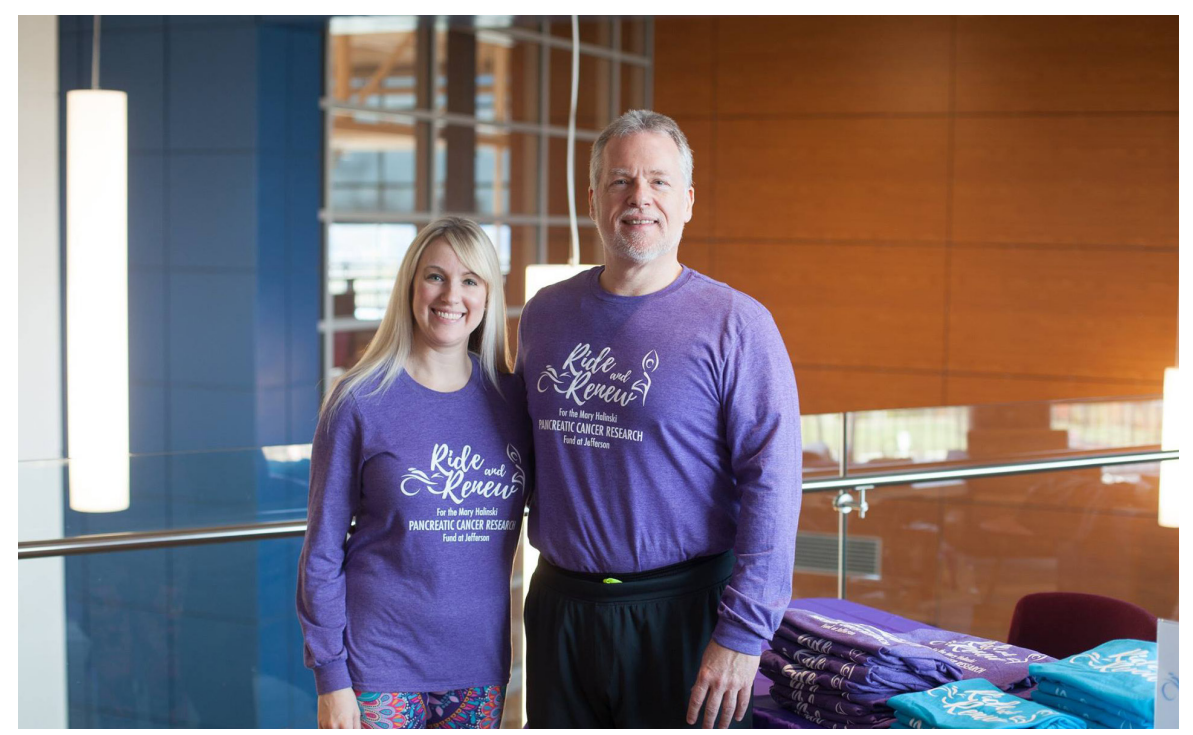




\title{
A PGY-1's Perspective:
}

\section{Conducting Pancreatic Cancer Research as a Medical Student}

\author{
BY: KEVIN XIE, CLASS OF 2021
}

Dr. Neal McCall graduated from Sidney Kimmel Medical College (SKMC) in 2018, and is now in his PGY-1 year at Emory University for his residency in Radiation Oncology. Dr. McCall first became interested in pancreatic cancer research after listening to Dr. Charles Yeo, Samuel D. Gross Professor and Chair of Surgery at Thomas Jefferson University, give a talk on pancreatic cancer during his first year of medical school. He reached out to express his interest and was introduced to Dr. Harish Lavu.

Dr. Lavu served as a crucial mentor for the formative phase of Dr. McCall's research career. Dr. McCall's foundations in clinical research are due to Dr. Lavu's strong influence and guidance, and he is tremendously grateful to Dr. Lavu for this. Dr. Lavu not only provided the direction and oversight to build a research skill-set, but he also provided enough space for Dr. McCall to grow and overcome obstacles on his own. This balance led to invaluable personal growth to which Dr. McCall attributes his early career success.

Dr. McCall's first project with Dr. Lavu, titled “Leakage of an Invagination Pancreaticojejunostomy May Have an Influence on Mortality," provided an archetype of how he would conduct and write his future projects. ${ }^{1}$ This experience played an important role in allowing Dr. McCall to participate in and contribute to subsequent projects. His time with Dr. Lavu has developed his skills and given him a strong foundation in clinical research. Dr. McCall was involved in several research projects as a medical student, and recently several of his papers were published. ${ }^{2,3}$

Dr. McCall's interests and research led him towards oncology, and he dedicated much of his time to learning and exposing himself to essential aspects of pancreatic cancer and the surgeries involved. For Dr. McCall, using his anatomy knowledge and appreciating the complexities of surgery was a cerebral experience, and it attracted him from the beginning. As medical school progressed and he

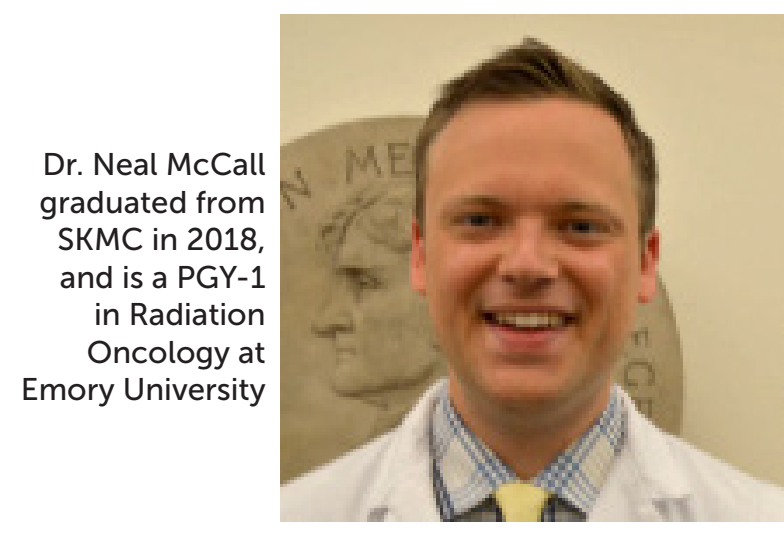

learned more about the care of pancreatic cancer patients, Dr. McCall stumbled upon the world of radiation oncology.

As Dr. McCall delved deeper into radiation oncology, his interest in the field grew, and he seriously began considering it as a prospective career path. He was drawn to the mix of patients, the variation in treatment plans, the courses of the diseases, and the option to cure or palliate. In Dr. McCall's own words, "You think about how you're planning it; you think about the dose, anatomic relationships, data collection, and collaborating with other people. I love those aspects of it, and I love that it's in a relatively low-stress environment. That's how I thrived on it."

When asked if there was a pivotal decision point in his career choice, he had to weigh how the different aspects of training and his intellectual interests aligned. Foremost, his passion is in oncology, and he was sure that he wanted to work with that patient population and be part of planning their care. Certainly, the training that medicine and surgery provide are quintessential for all paths in medicine, and either would have provided a robust clinical foundation in treating all patients. However, Dr. McCall recalled the main deciding factor to pursue radiation oncology to be the connection between planning for care and anatomy. "I like thinking anatomically, and there's something about thinking about anatomy that's really missing for me 
in medical oncology," said Dr. McCall. "I love the science and pharmacology of medical oncology," he continued, "but the reality is that you are actually involved in those things both as a radiation and surgical oncologist too. You're just not the one prescribing them. Regarding research trials, you still have to see the patients and understand the science behind it. That's certainly not missing in surgical and radiation oncology."

Dr. McCall knew from the start that oncology was his passion, and a career in Radiation Oncology was the right decision for him. The invaluable experience he had working with Dr. Lavu in pancreatic surgery provides him with an edge when it comes to understanding the intricacies of patients that are surgical candidates. Dr. McCall emphasized that the planning and decision making involved, coordination with other disciplines for neoadjuvant care, and post-operative care are all things he learned under Dr. Lavu's tutelage, and these lessons will guide his perspective on pancreatic cancer treatment in the future. Although Dr. McCall ended up not choosing Surgical Oncology as a career, he and Dr. Lavu continue to collaborate on research endeavors.

Dr. McCall's impressive research accomplishments werean essentialaspect of his residencyapplications, and lent him a competitive edge. His contribution to the WARP (Whipple Accelerated Recovery Pathway) trial was an important component of his application that captured the attention of his interviewers. Since many students do not have the opportunity to contribute meaningfully to a randomized clinical trial like WARP, the residency programs emphasized this experience in their interviews. Dr. McCall recounts that this clinical experience made him stand out amongst his fellow applicants. "Radiation oncology is an academic field. Everyone who is working in academics especially is passionate about research. It is quite a small field, and because of that, research is the most important thing, and it's hands down the thing that came up the most."

He also attributes much of his research and interview success to his work with Dr. Lavu, going on to say, "I don't think I would have been as successful in medical school. I think that building a strong clinical research background makes you a better doctor no matter what you do because you're just able to interpret evidence better than colleagues who don't have that experience. And you're able to actually apply it to patients who are right in front of you. So I don't think I would have been as successful during my M3 and M4 years, or even now, just because, in my opinion, that experience is really foundational for understanding how to practice medicine as a whole. Whether you're in surgery, medicine, or radiation oncology, that's a vital skill to have, and my experience with Dr. Lavu is what developed that skill overall."

\section{REFERENCES}

1. Lavu H, McCall N, Keith SW, et al. Leakage of an Invagination Pancreaticojejunostomy May Have an Influence on Mortality. J Pancreat Cancer. 2018;4(1):4551. doi:10.1089/pancan.2018.0008

2. McCall NS, Dicker AP, Lu B. Beyond Concurrent Chemoradiation: The Emerging Role of PD-1/PD-L1 Inhibitors in Stage III Lung Cancer. Clin Cancer Res Off J Am Assoc Cancer Res. 2018;24(6):1271-1276. doi:10.1158/1078-0432.CCR-17-3269

3. McCall NS, Simone BA, Mehta M, et al. Oncometabolism: defining the prognostic significance of obesity and diabetes in women with brain metastases from breast cancer. Breast Cancer Res Treat. July 2018. doi:10.1007/s10549-018-4880-1

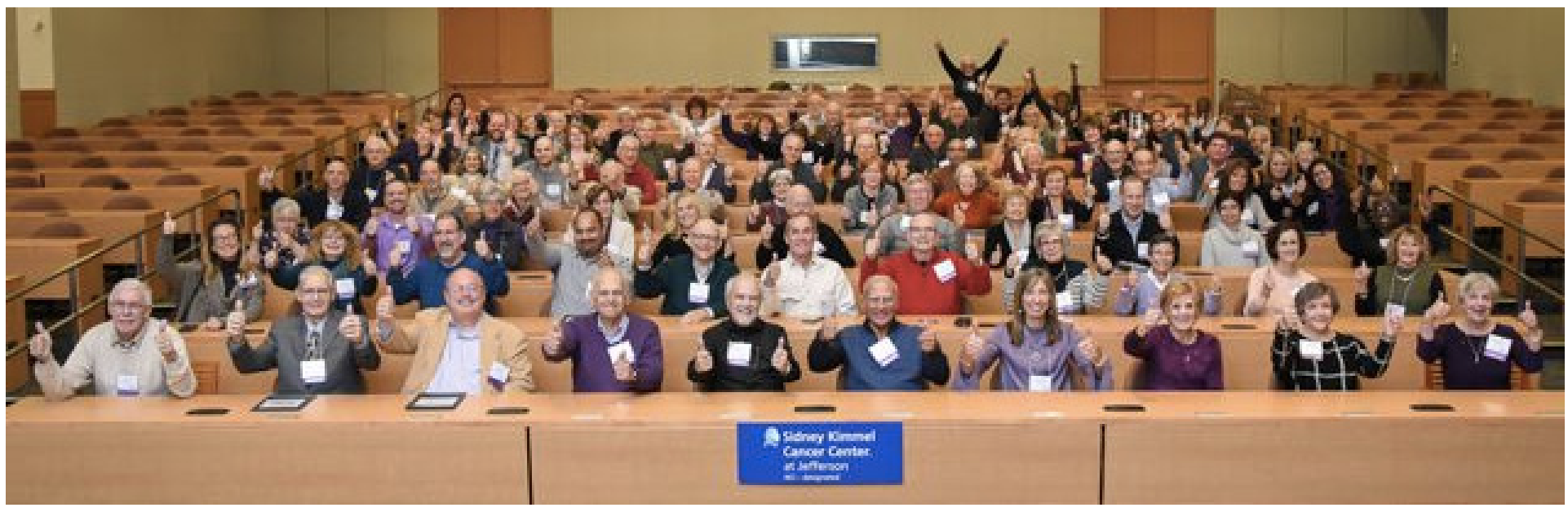

Survivors in attendance at the 2017 Pancreatic Cancer and Related Diseases Patient Symposium 


\title{
INTERVIEW
}

\section{Jonathan Brody, PhD Pancreatic Cancer Specialist}

\author{
BY: CARRIE DIANNE WALSH, CLASS OF 2020
}

\begin{abstract}
Dr. Brody is the Director of Surgical Research and Co-director of the Jefferson Pancreas, Biliary and Related Cancer Center. $\mathrm{He}$ is also the current Chair, Cancer Research Program (PRCRP), Department of Defense (Army) in Washington, D.C. The main focus of Dr. Brody's laboratory is to understand the molecular aspects of pancreatic cancer cells and find novel therapeutic strategies for pancreatic cancer patients.
\end{abstract}

During his over ten years of training at Johns Hopkins University, Dr. Brody began exploring drug-target interactions. Utilizing diverse molecular biology techniques that include DNA sequencing, gene knockout and silencing assays, and drug sensitivity assays, Dr. Brody has published extensively on aspects of chemotherapeutics, namely gemcitabine, 5-fluorouracil, and platinum-based agents. Part of this work includes his special interest in targeting cancer cells with defects in the BRCA2/ Fanconi anemia DNA repair pathway.

His work also includes advancement in the basic DNA detection technique of DNA electrophoresis, by discovering new and better alternatives to tris-based buffers, such as lithium-based buffers, that can separate DNA in a fraction of the time compared to conventionally used conductive media. In relation to gene regulation and mRNA stability, Dr. Brody aided in cloning members of the pp32 gene family over a decade ago. Members of this family, pp32 and APRIL, have been shown previously to be ligands and functionally interact with the RNA binding protein, HuR. Currently, Dr. Brody's work focuses on how HuR biology is involved in pancreatic tumorigenesis as well as cancer cell survival. His laboratory is also interested in how HuR expression levels and protein subcellular localization affects treatment of pancreatic cancer. Recently, the group published work showing that HuR subcellular localization can be potentially a valuable predictive marker for the standard of care with therapies for this disease. His laboratory's work is now primarily focused on HuR biology as it relates to the clinical management of cancer, including identifying clinically relevant HuR targets.

Finally, Dr. Brody is continuing his research in studying drug-target relationships as he is the principal investigator on a 1 million dollar grant (supported by the Pancreatic Cancer Action Network) that supports an unprecedented clinical trial testing a molecular based, personalized approach to treating pancreatic cancer patients

\section{CONCERNING RESEARCH IN GENERAL}

Q: When did you first develop an interest in research? Can you describe your general track to becoming a PhD? Did you make this decision in high school or undergraduate?

A: I actually attended my undergraduate institution (Skidmore University) on a music scholarship. I was a percussionist and I found my passion for music when I was diagnosed with juvenile rheumatoid arthritis as a child. I had been a soccer player until the age of 9 when I developed JRA, which left me confined to a bed for many weeks during the summer, not knowing whether or not I would be able to walk freely again. Luckily it was an acute episode over one summer and I regained full function, but it was during that time that my mom's friend, Linda, bought me drum sticks and drum lessons. For the rest of my schooling, I played percussion - I played vibraphone, marimba, and drum set.

Arriving in NY from a small town in Maryland, I appreciated pretty quickly how competitive a career in music was, and after doing an internship at the $\mathrm{NIH}$ one summer, I realized that many of the things I loved about music, like being creative, translated into research. I did think about a career as an MD, but with so many things in medicine that we do not have a cure for, I got really interested in cancer research and trying to help people in this capacity.

I did my PhD at Hopkins, which was mostly centered around cancer and molecular biology. For my fellowship, I worked for the researcher who described more mutations in pancreatic cancer than anyone in the world. It was through him that I found myself focused in on pancreatic cancer, and in fact I was part of the same team at Hopkins that included Dr. Yeo. Dr. Yeo came to Jefferson in 
2005, and started the pancreatic research program at Thomas Jefferson University Hospital. It was about a year later that he called me up and invited me to join his team.

\section{Q: How did you decide between pursuing an MD vs. a PhD degree (or both)?}

A: I played with the idea of doing an MD/PhD program, but I fell in love with being in a lab and doing research. I guess that I felt that it would be the best use of my talents, and the best way that I could help people.

I have so much admiration for clinicians who treat patients, and in fact I did a bunch of volunteering at various clinics during undergrad,

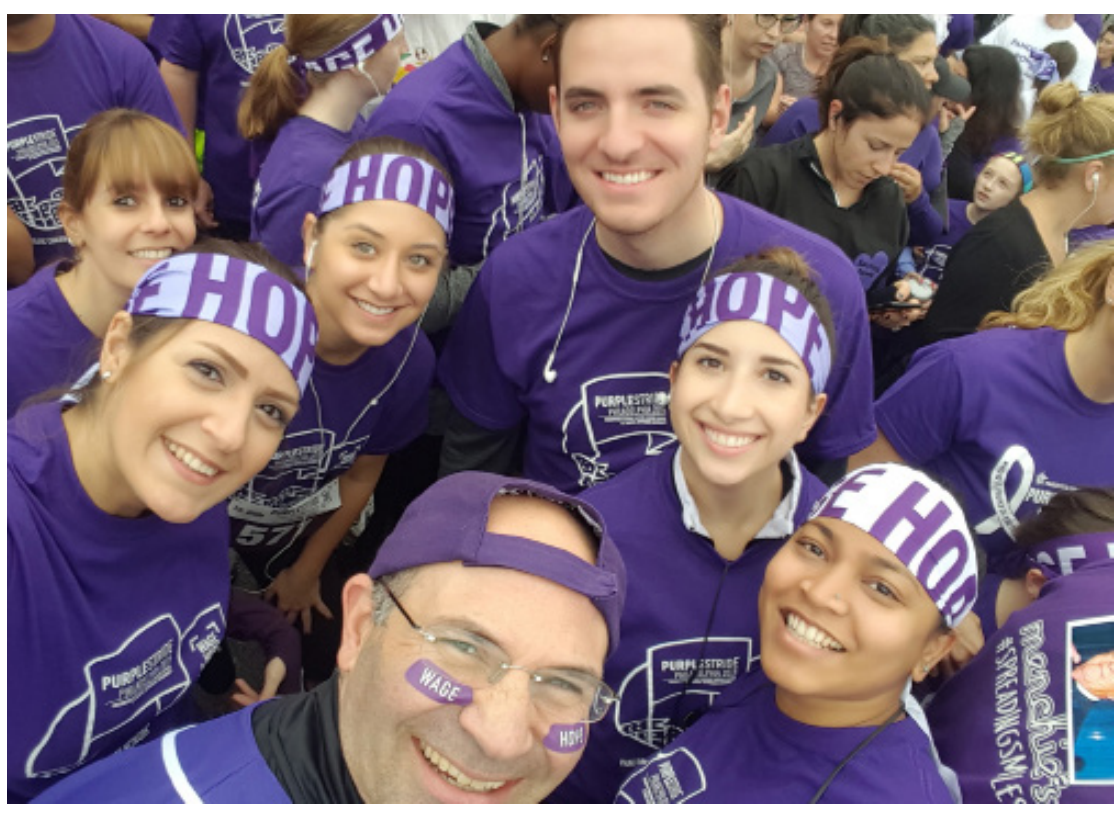

Dr. Brody with members of the laboratory at PurpleStride Philadelphia, hosted by the Pancreatic Cancer Action Network.

but I realized that it was very hard for me to treat a patient and then go home and live my life without becoming emotionally invested.

I enjoy being around people and mentoring students, but I wanted to push forward in our understanding of an untreatable disease, with the hope that we can eventually find a cure for our future patients.

Q: Who was one of your most influential mentors? What lessons did you take from this experience, and how do you use these lessons when it comes to mentoring other students?

A: I would say that my two most influential mentors were my drum teacher, and Scott Kern who was my postdoc fellow at Hopkins. Dr. Kern was also part of Dr. Yeo's group. I think that they both taught me that in order to best utilize my talents, to be creative and to perform at my best, I needed to be extremely prepared. In science, this means becoming as knowledgeable about a subject as possible before you work on it.

They also taught me the importance of thinking outside of the box, and how this method of thinking helps cultivate creativity both in the arts and in science. By constantly thinking in the box, you are not going to be able to make a difference. In fact, I wrote an article with my mentor from Hopkins on herd mentality in science, especially in the

biomedical sciences, and how the concept of group thought and herd mentality can be a bad thing for scientific progress.

And finally, my parents are my ultimate mentors, as they are true academics and teachers and they taught me the principles of: 1) never stop searching for the truth, and 2) teaching is the most important thing you can do to help society.

Q: I read that you joined Jefferson in 2006. How is your experience at Jefferson the same or different from your time at Johns Hopkins?

A: That is a difficult question to answer because I did all my training at Hopkins, which meant that I was fulfilling a different role there to the one I currently hold at Jefferson. I think that Hopkins is a great place to train, but I also think that whatever training program or institution you attend, what really makes the difference is the people you are with, and your mentors/professors.

I think that the core research faculty at Jefferson are extremely strong, and in some areas, even stronger than those at Hopkins. Additionally, people here at Jefferson are extremely collaborative - as I also found them to be at Hopkins. In fact, many people say that Hopkins is very competitive, but I always found everyone to be extremely cooperative at both universities.

One of the similarities between the two institutions 
is that both Jefferson and Hopkins are diverse enough that if we find something new and interesting in the lab, I can find someone within each of the institutions who is an expert. The other similarity is mostly because of Dr. Yeo. Dr. Yeo has developed both hospitals into high-volume centers for pancreatic surgery, which means that we have a large source of specimens to draw from, along with a database and important registry.

The multidisciplinary approach of both Jefferson and Hopkins, which brings researchers and clinicians together to try and make a difference - not just patient to patient, but globally - is extremely important.

Q: I read that you have over 120 publications in the peer-reviewed literature. What advice would you give to students, residents, and junior faculty members who are excited about pursuing a similar career in research? Would you have different advice for MDs vs. PhDs?

A: You have to pursue what is exciting for you. I also think that it is important to like the people you work for. One of my old mentors from Hopkins, Don Coffey, used to say, "Whatever you think about in the shower or when driving your car into work, that is what you are going to end up being good at, and that is what you should invest your time in."

For students, residents, and senior faculty, it is important to pair up with someone who has experience. If you see that someone has a good track record of publishing papers, they ask good questions, and they are a good mentor - someone like Dr. Harish Lavu - then connect with them and get their guidance. You need to find good mentors, but having said that, I do think that it is hard to find people who actually care about the process/ question and mentoring and are not just out for people to give them a paper. As a mentor, you have to roll up your sleeves and get to it because it is a two-way street. I am a firm believer that whatever time I put into students and residents will end up being an investment in the overall success of the lab and the work. It is also very fulfilling to see students and residents get excited about a project and follow through in the pursuit of trying to answer a good scientific research question.

The only thing I would say that is different for MDs vs. PhDs, is that you need to personalize your educational experience depending on what program you are studying in.
The accountability of the student is also important. I tell students all the time, "It is ok to knock on my door or email me." I want that accountability in a student.

Q: What advice would you give to junior MDs that are looking to become affiliated with PhDs for basic and translational research, similar to your relationship with Dr. Yeo? How did you go about picking the MDs/Institution to become affiliated with?

A: I think it is like any relationship, it does not have to be perfect, but there has to good chemistry, and you have to have mutual appreciation for one another. For instance, Dr. Yeo, who for me, is the epitome of the perfect surgeon - dedicated, on top of his game, and someone who expects the best from everyone - respects and appreciates what I do.

Dr. Yeo, Dr. Lavu, and I are a team with a common goal to make a difference for this disease, and if we can accomplish that, then the team wins. So, to answer your question, I believe that you have to find people with the same mission and values as you, and those that respect what each member of the team can bring to the table.

Q: Was there a moment or project that made you decide to dedicate your work to focusing on pancreatic cancer?

A: It was really my experiences at Hopkins that inspired me to dedicate my work to pancreatic cancer. This may sound very philosophical, but pancreatic cancer is one of those diseases that the more we know the less we know. Even though we know a lot, there is also a lot that we don't know, and for me, the challenge of that is very exciting. From a researcher's perspective, the expectations are high, and although I don't like these numbers for our patients, I'd rather dedicate my work to something where people are given a $9 \%$ chance to live five years vs. a disease like prostate cancer where patients are given a $90 \%$ chance to live five years.

Pancreatic cancer is a disease that is underrecognized and under-funded. There are not a lot of advocates out there because patients diagnosed with the disease usually get angry and then unfortunately pass away very quickly because of the poor prognosis that comes with pancreatic cancer. With long-term breast cancer survivors, they have time to get angry, time to fight the disease and 
survive, and then years to raise money and spread awareness. However, for pancreatic cancer, you are talking about typically a short survival period, which is heart-breaking, and people just have the time to get their affairs in order. It is just not fair.

Q: I read that you developed a ubiquitous tool in DNA analysis. Can you tell me a bit about that? Was this tool inspiration for some of your future research?

A: That project actually came from a mistake that was written in a lab protocol. I spent months working with that protocol before I realized that it was an error. It prompted me to ask the question, "Should we always accept what is written on a protocol?" The answer of course is no, we can always make improvements.

On realizing the error, I decided that it was something I could improve upon, and we ended up making a substitute for a new and better tool. The published paper allowed us to get a patent. Some of the students in my lab recently revisited my initial project and feel that they can better the technique by using a new technology, so we hope that we may be able to improve on the tool again.It is because of this experience that I often tell my students, "Don't just accept what is on the written page, always question whether you can do it better."

Q: I saw that you presented on CRISPR at Jefferson a few years ago. How has the development of this technology influenced you in recent years?

A: My lab has already published one paper using CRISPR technology, and both Dr. Jordan Winter and my lab are on the brink of publishing two more. From a research stand point, the technology is revolutionary - a phenomenal tool - and Jefferson is in the process of establishing a connection with Christiana Hospital to create a CRISPR institute.

Whether or not it will have a place in clinical practice is yet to be seen. There is a wonderful Ted Talk by geneticist Jennifer Doudna that you should check out. (https://www.youtube.com/ watch? $v=$ TdBAHexVYzc) It is definitely a very useful tool, but it needs some manipulation to apply it to the clinical setting.

Q: I saw online that you are involved in multiple projects with different institutions both in the United States and worldwide. Can you tell me a bit about your projects? And your collaboration between other national and international hospitals?
A: I think collaboration is great. My lab has 54 projects in process, and probably over 20 of them are collaborations with other institutions. We have a lot of collaboration with Israel, and now we also have projects with Kansas, Stanford, Columbia, Fox Chase, Drexel, and Georgetown. One of the great things about the pancreatic cancer community is that we are all very collaborative, there is some competition (we are all applying for the same grants), but the camaraderie is there.

One of my current projects is with Oregon Life Sciences in Portland. We are writing a grant to create a live bio bank of specimens, so that we can do molecular and drug studies on live tumor samples. It is a huge project, and something we are all very excited about. I am also part of a precision medicine endeavor, which is a multi-institutional project.

I think that my partnership with Dr. Yeo opened a lot of doors for me, both nationally and internationally, and since my lab's opening, our work has been strong enough that people want to collaborate with us. For example, I just returned to the States from giving a talk in Manchester, UK as I have a nice collaboration there too.

For the most part, people who go into research in pancreatic cancer want to make a difference. I think that we as researchers realize that success correlates to teamwork, communication, and collaboration. If you are going to make a difference with this disease you cannot work in silo.

\section{CONCERNING PANCREATIC CANCER}

Q: What do you think have been the greatest recent advances in the field of pancreatic cancer medicine and surgery? Do you think there is a field-changing advancement on the horizon for pancreatic surgery? For cancer as a whole?

A: I think that the way we are starting to manage the disease shows that we are getting better at treating it. The surgery aspect of it at Jefferson is outstanding, and we are also getting better at controlling people's pain.

There are some recent data that have evaluated different ways of treating the disease. For example, neoadjuvant vs. adjuvant therapy, or both. Although not completely decided on, recent studies have indicated that neoadjuvant therapy might be the way to go in certain instances.

The personalized side to pancreatic cancer 
treatment is still in its early stages. I was part of a paper that showed that a decent percentage of patients have mutations that could potentially respond to drugs that are already in circulation as treatment for a different disease. There are a lot of targeted therapies in the lab that I am excited to move to the clinic, but doing a specific clinical trial is difficult, especially for the rarer mutations.

I think that our general understanding of the disease has been enhanced in recent years through our discovery that pancreatic cancer is not just made up of tumor epithelial cells, but that there is a tumor micro-environment that involves things like stromal cells and fibroblasts. So the main question we now have is: how do we navigate and target that?

I think there is hope, and I think that there are going to be some major breakthroughs in the next 5 to 10 years. We keep creeping up in our 5-year survival percentages, from $6 \%$ a few years ago to $9 \%$ now. We are better at managing patients clinically, and I think that will dove tail when we start being able to use personalized treatments and expand our drug arsenal.

Q: In your view, are there any current projects in the field that may dramatically change the detection or treatment of the disease in the near future?

A: There are a few projects that are really exciting. There is a drug called pyrvinium pamoate, which is currently a treatment for pinworms, which can target a molecule that is very pro-oncogenic. We think that it could be a good sensitizer for current drugs or even act as a monotherapy for treatment for pancreatic cancer. We are in the process of completing the pharmacokinetic studies for this project, and we hope to do a clinical trial next year.

Q: I saw on your Twitter feed that you attended TRIP18, the first Israel Symposium on Pancreatic Cancer. Do you find the treatment of pancreatic cancer to be an international field, and if so, are there particular groups internationally that have influenced your research projects?

A: My collaborator in Israel, Talia Golan, (Sheba Medical Center in Tel Aviv) has a very unique population. She has the highest volume of Ashkenazi Jews with pancreatic cancer who have the BRCA2 mutation. She has developed cell lines from these patients, which she sends over to me so that we can use them in our lab.

We also have a partnership with Hebrew University to study a biochemical RNA binding protein, and of course our affiliation with Manchester, UK.

\section{OFF THE WALL QUESTIONS}

\section{Q: What was your first published paper on?}

A: I am really aging myself here! But it was on the cloning of a gene. This was before the internet, in the early to mid-90s. My project focused on cloning this gene and studying its properties. One of the reasons I am now currently studying the HuR protein is because it is linked to that gene.

Q: If you could go back in time and tackle your past projects in a different way, what would you change?

A: This is something that I often ask myself. I would say that I tend to be very incremental in my work, and sometimes I wonder whether thinking bigger is a good thing. However, there is also a financial cost to thinking too big too soon, because sometimes it is the journey that allows you to discover the big picture.

The pyrvinium pamoate project has taken about a decade to reach the clinical trial phase because we got there through a series of steps, and I do not know if we would have gotten there if we had not followed that path. In a way, you have to earn those big ideas and breakthroughs. It is always about the journey.

\section{Q: Do you still play the drums outside of work as a release to help you prevent burn out?}

A: I used to use the drums as an outlet, but now with running a lab and having a seven-month-old at home, it makes it very difficult. When I first came to Jefferson, I played in a band with the medical students. I still hold my drum set and want to play, but for now I use that extra energy to go and listen to live music.

\section{Q: What other things do you enjoy doing in your spare time?}

A: Traveling with my family. My wife and I, and our baby, have been to Israel, the UK, and Italy this year. We were able to link to some scientific conferences. We are very fortunate that the little one travels well. And then of course, exercise and listening to live music. I love to play basketball. A group of the guys and I will get up and play basketball at 6am. It keeps me young! I also love running and being outdoors. 


\title{
RESEARCH SPOTLIGHT
}

\section{The Journal of Pancreatic Cancer}

\author{
by: Harold I. Salmons, Class of 2020
}

\begin{abstract}
In the realm of oncology, cancer of the exocrine pancreas is an especially lethal malignancy. Annually, exocrine pancreatic cancer is the third leading cause of cancer death in the United States and the eighth leading cause of cancer death worldwide. As the organ itself is embedded between key vasculature and digestive and biliary organs, pancreatic cancer is a very challenging disease to treat. At the moment, surgical resection is the cornerstone of the only curative option for exocrine pancreatic cancer. Unfortunately, the disease classically presents late, and only a minority of patients qualify for surgery at the time of diagnosis. Research is therefore a key measure in trying to address this disease and hone its cures.
\end{abstract}

Efforts are underway worldwide to understand the molecular and clinical manifestations of pancreatic cancer, and further refine its medico-surgical treatment. The Journal of Pancreatic Cancer (JPC) is the only peer-reviewed journal focused exclusively on pancreatic cancer. Led by Editor in Chief, Samuel D. Gross Professor and Chair of Surgery at Thomas Jefferson University, Charles J. Yeo, MD, this international journal offers open-access, peer-reviewed articles covering the clinical, translational, and basic science of malignancies of the pancreas and the peripancreatic region. The JPC is a terrific resource to surgical oncologists, pancreatologists, gastroenterologists, radiation oncologists, medical oncologists, endocrinologists, pathologists, palliative care specialists, epidemiologists, immunologists, and cancer researchers investigating problems and treatments for pancreatic cancer. From molecular genetics to surgery, this journal offers the most broad and thorough investigation of pancreatic cancer-related research topics.

The Jefferson Pancreas, Biliary and Related Cancer Center serves as a shining example of what can be accomplished in the field of pancreatic cancer research. The team of surgeons, oncologists, gastroenterologists, and researchers have emerged as pioneers in the field of pancreatic malignancies, both through their research efforts and their recognition of key surgical findings that are uncovered during their operations. This article intends to highlight some of these achievements by casting a light on a few of Jefferson's more recent impactful publications in the Journal of Pancreatic Cancer.

\section{Surgeon-Led Imaging Review for Patients with Periampullary Disease: An Important Aspect of the Preoperative Consultation ${ }^{1}$}

At surgical consultations, an abundance of radiologic studies often accompany a patient. Despite being common practice during patient visits involving the discussion of upcoming procedures, there is a paucity of literature specifically investigating the benefit of incorporating the actual viewing of their own images by the patient. The possible benefits of utilizing imaging as a means of educating patients include facilitation of a better understanding of one's diagnosis and more active participation of the patient in their care plan. This article is the first to examine these perceived benefits to educate and include patients in their care plan. In this study, patients with pancreaticobiliary surgical consultations were surveyed before and after their appointments, during which a surgeon scrolled through CT and/or MRI scans with the patient and family. Using a five point Likert scale, patients reported their perceived importance of viewing their imaging studies and understanding their medical conditions. Of 51 patients surveyed, 78\% reported they had not previously seen their imaging, and $55 \%$ of patients thought it was important for them to do so. On average, surgeons spent 2.7 minutes reviewing imaging studies with patients and family. On the post visit survey, $90 \%$ and $86 \%$ of patients, respectively, responded positively to better understanding their disease and their planned operation having seen the imaging studies. After these appointments, almost all patients felt that the imaging review with their surgeons was valuable and enhanced their understanding. Based on the findings of this study, the authors argued that surgeons should incorporate imaging reviews into their patient encounters.

\section{Leakage of an Invagination Pancreatico- jejunostomy May Have an Influence on Mortality ${ }^{2}$}

Whipple procedures are currently the gold standard for treating pancreatic ductal adenocarcinoma (PDA). The most common complication of this 
procedure is a postoperative pancreatic fistula, which is a leakage of amylase-rich fluid from the site of the pancreaticojejunostomy (PJ). Among the three anastomoses performed for pancreatic reconstruction, the $\mathrm{PJ}$ is generally considered the "Achilles' heel" of the procedure, due to its significant importance in patient recovery. There is no consensus regarding the most effective form of PJ following a Whipple procedure. To mitigate the risks of fistula, many techniques have been studied: alternative anastomotic techniques, the use and management of intraperitoneal drains, fibrin glue, and pharmacological agents, but none have proven definitively effective. The two standard PJ anastomotic approaches are invagination PJ (IPJ) and duct-to mucosa pancreaticojejunostomy (DmPJ). In this study, Dr. Harish Lavu's team aimed to retrospectively compare morbidity and mortality between IPJ and DmPJ using the multi-institutional American College of Surgeons-National Surgical Quality Improvement Program (ACS-NSQIP) Pancreatectomy Demonstration Project. Patients who received a DmPJ or IPJ differed with respect to preoperative and intraoperative variables, hence the groups were not strictly identical. The authors concluded that IPJ leaks may have a greater influence on mortality than leaks in DmPJs, and that further study is warranted.

Pancreatic Mass in a Patient with a History of Resected Renal Cell Carcinoma and Resected Adenocarcinoma of the Ampulla of Vater: A Case Report $^{3}$

Metastasis to the pancreas from a different primary cancer site of origin is rare. This report presents a fascinating case in which a patient with past renal cell carcinoma (RCC) status post-left nephrectomy and ampullary adenocarcinoma status postWhipple had a metastasis to his remnant pancreas. This patient underwent resection via completion pancreatectomy, which revealed pathology consistent with metastatic RCC. This paper discusses the importance of timing in regard to properly identifying a primary versus metastatic tumor. Metastasis of RCC to the pancreas often presents many years after a primary resection. Conversely, recurrent PDA often presents within 5 years of resection. Additionally, if one resects the RCC tumor, outcomes are often better than if one resects a recurrent PDA. The authors of this paper recommend resecting suspected isolated pancreatic RCC metastases due to these known favorable outcomes, however this is still a highly debated topic.

\section{Perioperative Management of Factor V Leiden and Pancreatic Adenocarcinoma ${ }^{4}$}

The perioperative management of a patient with Factor $\mathrm{V}$ Leiden has been infrequently reported. Further, before this article, there were no reports of the management of this disorder during pancreatic surgery. This report was of a 74-year-old woman with known Factor $V$ Leiden disorder (which causes increased clot formation), who came to her primary doctor with pruritis, tea-colored urine, pale stools, andjaundice fora week. She hadaCT-confirmed mass of her pancreas and underwent a pylorus-preserving Whipple procedure. She did not have immediate perioperative embolic or thrombotic phenomena. Despite being a common hypercoagulable disease, this was one of the first case reports in the literature describing the management of a patient with Factor $V$ Leiden disease undergoing pancreatic cancer surgery. The successful management of patients with hypercoagulable states undergoing surgery involves anticoagulation medications, such as low molecular weight heparin or a heparin to warfarin bridge, for a minimum of 3 months. However, the authors discuss the challenges of avoiding bleeding events in surgery patients on anticoagulants, and consequently these risks must be considered while managing these patients.

\section{REFERENCES}

1. Latona JA, Tannouri S, Yeo TP, Cannaday S, Lavu H, Winter JM, and Yeo CJ. Surgeon-Led Imaging Review for Patients with Periampullary Disease: An Important Aspect of the Preoperative Consultation. Journal of Pancreatic Cancer. 2018; online ahead of print.

2. Lavu H, Mccall N, Keith SW, et al. Leakage of an Invagination Pancreaticojejunostomy May Have an Influence on Mortality. Journal of Pancreatic Cancer. 2018;4(1):45-51.

3. Kling SM, Tannouri S, Jiang W, Yeo CJ. Pancreatic Mass in a Patient with a History of Resected Renal Cell Carcinoma and Resected Adenocarcinoma of the Ampulla of Vater: A Case Report. Journal of Pancreatic Cancer. 2018;4(1):4144.

4. O'Malley TJ, Sooppan R, Yeo CJ. Perioperative Management of Factor $\mathrm{V}$ Leiden and Pancreatic Adenocarcinoma. Journal of Pancreatic Cancer. 2017; 3(1): 53-57. 


\title{
The Mary Halinski Pancreatic Cancer Research Fund and its Impact on Pancreatic Cancer Research at Jefferson
}

\author{
by: Samantha L. Savitch, Class of 2021
}

\begin{abstract}
I had the pleasure of speaking with Bob Halinski, founder of the Mary Halinski Pancreatic Cancer Research Fund, and Dr. Harish Lavu to discuss the state of pancreatic cancer research. Bob founded the Halinski Fund in honor of his late wife, Mary, who passed away from pancreatic cancer in 2013. Along with his daughter, Stephanie, and son, Luke, Bob hosts a fundraiser every year called "Ride and Renew" to raise money for research endeavors at Jefferson and educate the community about this important disease. Bob is the recipient of the 2018 Community Impact Award for his work as a fundraiser and advocate.
\end{abstract}

Q: Bob, you clearly developed a strong relationship with the physicians at Jefferson who took care of Mary. Can you describe what brought you to Jefferson in the first place and how you met Dr. Lavu?

$\mathrm{BH}$ : We went to Jefferson based on the recommendation of our PCP, largely because of Dr. Charles J. Yeo's reputation. We made an appointment as soon as we could after the initial diagnosis. Interestingly enough, when Mary went down [for] a procedure to put a stent in, because she was having a blockage, we had assumed we had made the appointment with Dr. Yeo, but then Dr. Lavu came into Mary's room while she was recovering from the procedure. And at that point there was an instant connection. Dr. Lavu had a wonderful bedside manner and seemed very intelligent, and had a very calming demeaner. Over the course of Mary's treatment at Jefferson, the two of them really developed a patient doctor relationship, they befriended one another.

Q: Dr. Lavu, what do you remember about Mary from that first encounter?

HL: I remember Mary as just an unforgettable type of person. Mary was a high energy person, a person who just has a thousand-watt smile, that kind of a person. We hit it off right away.

Q: Bob, do you think that relationship played a big role in how your family was able to deal with the course of the disease and the hospital visits?

$\mathrm{BH}$ : Definitely. Really all of the physicians down there, including the nursing team, but Dr. Lavu mainly for the surgical management and then on the medical side Dr. Edith Mitchell, who again had a wonderful bedside manner with Mary. Mary was always a pleasant person, easy to get along with, and people just gravitated toward her, and she just befriended Dr. Mitchell too and they became friends. We had many visits with her, a lot of it was just, not only the medical part, but on the personal side too. I think it helps to know you're in good hands, and there's a compassion there that's real. It's not a forced compassion. The way I viewed it, and I know Mary viewed it, it was real compassion for patients, real compassion for Mary, and when I go to these symposiums and am sitting around the table there and talking to patients or caretakers, they all have the same message: not only great clinical care, but the compassion they feel. And I think that is helpful in dealing with the diagnosis.

Q: How has your relationship with each other changed over the years?

$\mathrm{BH}$ : It's interesting, Mary had the connection, not that Dr. Lavu and I didn't have a connection, but we weren't as close, so to speak. I think that once Mary passed, not only was it tough on me, but I think on Dr. Lavu, it really moved him, and it was tough on him because he really wanted Mary to survive longer than she did. I know that the doctors have to be professional, but you're human too, and I think by establishing the fund, I was able to continue the relationship with Dr. Lavu, where we'll touch base periodically on a friendship basis, and partly also on a professional basis, as far as getting updates on where things are going with pancreatic cancer research. So I sort of stepped in the shoes of Mary a little bit, not so much because that was a special relationship they had, but I call Dr. Lavu a friend and I think likewise he probably feels the same about me.

HL: We're very close, because we shared an experience. Obviously, Bob was there every step of the way for his wife. We developed a closeness 
through that process that lasts to this day.

\section{Q: While Mary was going through treatment, were there any experimental options that were offered to her?}

$\mathrm{BH}$ : There were some clinical trials that were made available. Mary was in a couple different ones, but not anything groundbreaking. One that Mary didn't do, and I think there was a little bit of disappointment on Dr. Lavu's side and some of the researchers there, was a vaccine trial that was going on. Mary was a clinical person, she worked at a pharmaceutical company, she had a science background, so she understood all of that. I'm a finance person so it was always difficult for me. But for that one clinical trial, we both did our own independent analysis of it, and came back with the conclusion that we didn't think it was worthwhile. There was no regret on the decision. You make the decision based on what you have. We never second guessed that. We just trusted our judgment. Sometimes you have to face what's staring in front of you.

Q: Tell me about Mary's background. I hear she was a big player in patient advocacy. What drove her to be so involved in the community?

$\mathrm{BH}$ : Part of it is just her personality, it's just her character and her makeup. She was just a giving person. She always looked to help others. She would help not only to take care of me and my two children, and her mom, but she was just a giving person across the board. My son had a lot of health issues when he contracted undiagnosed Lyme disease, and he had a lot of pretty significant adverse manifestations from that, and she took it upon herself to be an advocate for patients. She was very good politically - reaching out to federal legislators, state senators, and trying to get legislation that could direct funding toward Lyme disease research. She just liked helping people. Every day of her life she liked to help people.

\section{Q: How did the idea for the Mary Halinski Fund come to be? What did it entail to put it in place?}

$\mathrm{BH}$ : Mary really appreciated what Jefferson was doing for her, and the care that was being provided throughout her whole treatment, so she made donations to the existing Jefferson pancreatic cancer research fund. After she passed away, [I thought about] her whole legacy of giving and being an advocate for patients, for people, and helping people across the board. Laura Goldstein [of Jefferson's philanthropy department] had reached out to Mary thanking her for the donation, so I sent a note to Laura, and said, "Hey, if I want to do something in Mary's name, what could I do?" The idea of a research fund in her name just seemed like the perfect fit, for me and for Mary. It kept her legacy of giving alive. She loved science, she loved learning, she loved helping people. And I thought if I start an endowed fund in her name, what better way to honor her legacy? If research advances are made by the Jefferson research team, and it's published and they make advances at some point, I would love Mary's name to be part of that. And that's why I thought that was the way to go. And I felt really good about it, and it helped me. When somebody you love dearly passes away, this is a way to have some positive come out of, and it accomplished that. It helped me in the healing process to try to move forward, and the continuation of the fund has been helpful. And the thing that's amazing is there's a lot of things in this world that don't go right, but there's a lot of goodness in this world too, and when you establish a fund like this, it's just nice because people step up to the plate.

Q: What does the fund look like now? What are the main goals and what types of events are associated with it?

$\mathrm{BH}$ : Our fund is not the largest fund in the world, but it's a start. I think part of the fund is to use it to seed research. To get the multimillion dollar grants, you have to have a testing ground to prove to whoever is providing that grant, whether it's a private foundation or the government, people want to see, "Is this going to work?" That's really what our money is being used for. The main fundraiser every year, which we started a couple years ago, is called "Ride and Renew". It's a one-day event, and it's a combination of indoor cycling, spin classes, and yoga classes. I've become an avid cyclist and yoga is great for me to improve my health and has helped me move forward after Mary's passing. My daughter also enjoys cycling and recently became a certified licensed yoga instructor, so we just found that this would be the right fit for us to have some forum to raise money, help physically and mentally too, and it gave us a venue to get the word out. We just want to get Mary's name out there and keep her name alive, but also let people know about pancreatic cancer. As you know, it's so lethal. All cancers are bad, but this one seems particularly lethal. I don't think people know that, and when they hear the statistics, it touches them. So that's what we do, and this will be our third year now. It's been received pretty nicely, and we're happy about it.

This year's "Ride and Renew" will be held on Sunday, 
November 18th.

\section{Q: What has your involvement in the pancreatic sphere been outside of the fund?}

$\mathrm{BH}:$ I just support the other organizations. I support their events. I try to show up to those, any one that's local that I can drive to I'll usually go and support people. Everybody just sticks together on that. I'm not active in any other way than participating and making contributions to those funds. I like the money to go to Jefferson, but these other organizations do wonderful things too.

Q: You're being given the Community Impact Award at this year's Pancreatic Cancer Symposium. Can you tell me a bit about when you found out about that award and what it means to you?

$\mathrm{BH}$ : I received a letter from $\mathrm{Dr}$. Yeo directly telling me about this inaugural award and that they'd like me to be the recipient and outlining why. My first reaction was, "You guys don't need to do this." I appreciate the award, but I just want to do what I'm doing and help. But I am grateful for the acknowledgement, because I do try to make an impact. But it's about Mary and it's her award and her fund, and it just needs to be about her. The thing I like about it is, if in the course of getting this award and telling my story, maybe it can help people who have gone through a pancreatic cancer diagnosis move forward. Maybe people will think, "This guy encountered this and he's doing pretty well and trying to make a positive out of a negative." And that actually makes me feel good about this.

Q: Dr. Lavu, how has Bob's work influenced the community and how does he embody this award?

$H L$ : The thing that's been really impressive is that Bob went through this experience with Mary, [and] he could have left it with that and just let it be. But he decided he wanted to do something, along with his daughter, Stephanie, and his son, Luke. And not only have they supported research and donated their own money, but they've hosted a fundraiser which serves the purpose of raising money and getting education out there to the community. And to me that's so amazing. That's so critically important, because people out there don't know a lot about pancreatic cancer. I've been able to attend a number of the events that Bob and Stephanie have put on, and they've been great. And then Bob has been supportive of other families and other groups who have put on their events. We've met at other people's events, he's been supportive of them. He's one of these glue people, I think, a person who brings other people together, that's how I think of Bob. I just think it's really fitting that he's getting this award.

Q: What do you see as the biggest impact that the fund has had on the pancreatic cancer sphere?

$\mathrm{BH}$ : Just in general, when I hear about some of the small advances that they're making in findings, I just feel really good. I know the research takes a while to run its course to really make a difference, but what I like is when I hear the little advances they discovered in six months and how they plan to use it, that's what excites me. I get reenergized. I sit down with the researchers every six months, and when I leave there, I think, "Okay we're making a difference here." You publish this, other researchers will look at it, and they will say, "I like that idea let's run with this coupled with something else." That's how I view the fund.

$\mathrm{HL}$ : It's been tremendous helping us continue our pancreatic cancer research here. The things we do clinically, we work together with our basic scientists such as Dr. Jonathan Brody. And the Halinski Fund covers the funding for young researchers to carry on this work and to train the next generation of researchers and basic scientists. Ultimately, the next great leap forward will come from a laboratory. And we all know that, even as clinicians as we take care of patients every day. So for us, it's very important to have a fund like that.

Q: Dr. Lavu, what does the field of pancreatic cancer research look like right now?

HL: Pancreatic cancer is being attacked on so many different fronts, whether it's early detection strategies, whether it's new targeted therapies, whether its understanding how to use chemotherapy more effectively. In the surgical field, in the last ten or fifteen years, we've become much more aggressive in the kind of surgeries that are being done. We're doing more minimally invasive surgery. We understand how important it is to get the patients through recovery so they can get on to adjuvant therapy. And that has improved lightyears in terms of postoperative and preoperative care. Ultimately, there will be breakthrough medications that will be developed that will put pancreatic cancer more on a par with breast cancer or colon cancer, which are cancers that are treated in very similar ways to pancreatic cancer: surgical 
resection, chemotherapy, sometimes radiation therapy. But the main difference is that, for those cancers, the chemotherapy is incredibly effective, and for pancreatic cancer we're not there yet.

\section{Q: What is a reasonable goal for five years from now?}

HL: We know that the incidence of pancreatic cancer is rising. By 2020 it will be the second leading cause of cancer death in the US. And that is being driven by demographic forces: the aging population, aging smokers, and then the crisis of obesity and metabolic syndrome. All of these are driving pancreatic cancer development. When I first had the inkling that I might even be interested in this field, 18 years ago, the number quoted in research papers for five-year survival was very low, but it has been slowly inching up since. In five years, my hope is we can double the survival rate that we see today, because the pace of knowledge, the pace of scientific research is accelerating. I think that's a reasonable and realistic goal. In fact, I want it to be better. I hope it can be even better. I hope I'm underselling it.

Q: Are there any recent findings or research on the horizon that could prevent stories like Mary's from happening?

HL: There was literally a breakthrough in our understanding of adjuvant therapy for pancreatic cancer just three months ago. A large-scale, multicenter trial showed that combination chemotherapy, that people thought was too aggressive for patients after surgery for pancreatic cancer, it turned out it did a fantastic job in preventing recurrences and prolonging people's lives. That was a huge, huge breakthrough. And it changed the standard of care almost overnight. The patients we see today are being advised to get a combination chemotherapy that they were not advised to get in May of this year. That's how quickly it's changed. And that's why I say the pace of development is accelerating in our society, for everything, and I think that it will serve to help pancreatic cancer care.

Q: I read that the Halinski Fund contributed to the Jefferson study looking at HuR. How influential has the Halinski fund been on pancreatic cancer research at Jefferson?

HL: I think [the fund] has been a pillar of helping support pancreatic cancer research here at Jefferson. And the HuR story is one of the important molecular themes in pancreatic cancer development. Dr. Brody's lab is amongst the world's leaders in understanding HuR. I just think it's very exciting, and I know that the researchers who are being funded to be able to do this work through the generosity of the Halinski fund, these are your next generation of Gl cancer researchers. So I just think it's an immeasurable impact.

\section{Q: What do you each see as the role of health care professionals in these kinds of funds?}

$\mathrm{BH}$ : Awareness. Physicians, your focus, and rightly so, is on the clinical aspects of it, and trying to heal the patient or make their quality of life better. That's why you go to medical school, to treat patients. But I think that for a fund like this, the physician's role is just to let patients know that there are funds like this, that are helpful for your ability to give back, or make a positive difference. So don't be averse to it. People say that's the development people's job to raise money and awareness. But I think the physicians need to collaborate and work and I think Jefferson does a good job of that, you know the balance between the need to get funds for research and help as best they can.

$\mathrm{HL}$ : I think that the bottom line is I' $m$ in the field of pancreatic cancer care as a doctor, as a surgeon, as a researcher. And philanthropy is one of the ways that one advances the field. If you look at funding for cancer research from the $\mathrm{NIH}$, pancreatic cancer is tremendously underfunded. The $\mathrm{NIH}$ and the $\mathrm{NCl}$ have not caught up with the proper funding levels to look for the breakthroughs that we have gotten for breast cancer, for colon cancer, for melanoma. There are amazing stories out there for some of these other types of cancers, and most of those stories started in basic science labs. So philanthropy is one of the ways that pancreatic cancer research is being conducted these days. My role is to get that message across.

Q: Dr. Lavu, as a healthcare provider, how would you bring up philanthropy to a patient, student, or other person in the community?

$H L$ : I think that different doctors do it in different ways and have different comfort levels. Certain people have a natural ability to bring up things like that. I do think it's important to recognize though that when you're caring for a patient, for a family, it's really critical that you have a close bond and it's all related to medical care. The philanthropy picture is something that comes up later on, down 
the road, when your direct care is mostly finished at that point. But oftentimes patients or families will say, "What can we do to help?" And there is a lot of research that shows that people who have been through a medical condition or family members, there's a feeling of helplessness. Because you've gone through this thing, and maybe you've made it out the other side, but you feel like, "What can I do to help other people?" And there's a lot of research that says that being involved with philanthropy is tremendously healing for patients that undergo these traumatic medical experiences of having illnesses. So for the people who are interested in that way, I enjoy chatting with them about it.

Q: What would you say to people who are interested in their own funds or donating to funds? What is the process like?

$\mathrm{BH}$ : If you're thinking or inclined to be doing something, really think about it seriously, because you're going to feel good about it. I always tell folks to act upon that, whether its setting up a fund in a loved one's name, that's great, but Jefferson has a wonderful existing fund too. And it really does make a difference. Every dollar counts. Jefferson is really good stewards of that money, and they are using it essentially $100 \%$ for research. It's not going to overhead or anything else. And the process is very simple, but can be pretty customized to what your needs and desires are. The development team is just really nice to work with.
HL: We have a liaison between our surgery department and the philanthropy office at Jefferson. They work very closely with us because they're involved in helping run a lot of pancreatic cancer awareness events and things of that nature. So if a patient or family member is interested, I'll just serve as the person who puts two people together.

\section{Q: Is there anything else you want people to know about Mary or the fund?}

$\mathrm{BH}$ : Mary was just a special person. She just gave so much of her time for others. She volunteered, she was a very strong person of faith, and she relied on that to help her deal with everything. She donated a lot of time to her church, and she visited nursing homes and the elderly and prayed with them as part of the Catholic faith. She donated her time to going down to the soup kitchen to feed the homeless. She just helped people all the time. That's who she was. She was a selfless person, but very positive too. She'd make friends instantly. She went to jury duty and she got there and had all these friends. And I was like, "How did you make friends with jurors so quickly?" But that's the person she was. She just connected with people. She was selfless and giving and had a strong faith in God and it was wonderful to see that. And it's helped me and motivated me in lots of ways. And that's why this fund is a way to continue to honor her. She loved to give to people and give herself, and this is the perfect thing for her.

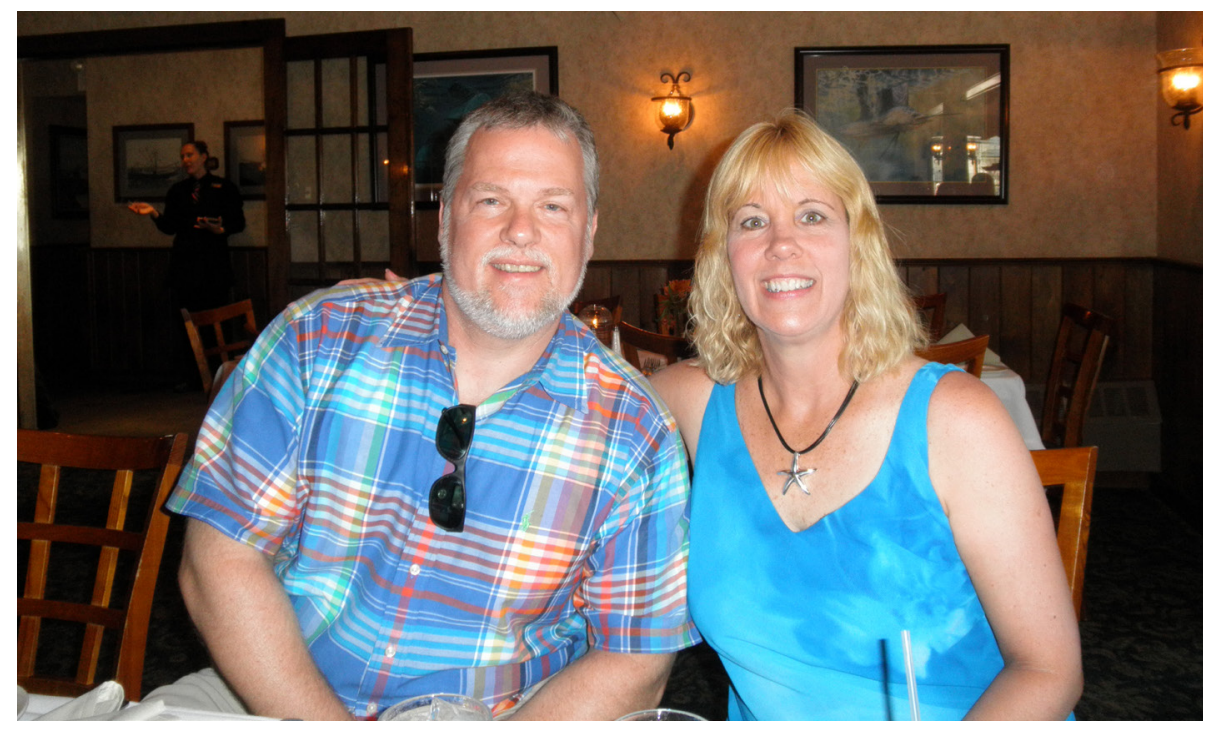

Bob and Mary Halinski in August of 2011 


\section{THE GIBBON SURGICAL SOCIETY}

The John H. Gibbon, Jr. Surgical Society (GSS) at Sidney Kimmel Medical College (SKMC) at Thomas Jefferson University is a unique student interest group that has been working hard to increase interest in the field of surgery among medical students for the last 37 years. The society has over 400 total active members on a year to year basis, spread across the four-year curriculum. The GSS increases exposure and interest to the surgical field through a unique blend of episodic and longitudinal programming that helps bring together students, residents, and faculty in an educational setting.

The crux of the GSS approach to bolstering medical student interest is early exposure. Over the years, the GSS has run many programs specifically targeted at students in the pre-clinical curriculum to increase surgical exposure. Potentially the most influential program is Surgery at Night, which provides an opportunity for students to spend an overnight shift with a surgical resident and intern early in their medical school career; there are typically over 200 such overnight stays by students in an academic year. Students frequently have the opportunity to scrub in on emergent cases and are often instructed in suturing small incisions at the end of cases. Another excellent opportunity for students is the Organ Procurement Program, in which all students who receive the necessary training are signed up for a lottery that allows them to travel and scrub in with the organ procurement team. The most innovative program that has been started by the GSS is the SCALPELS program, in which faculty members and upperclassmen plan a longitudinal surgical curriculum that runs concurrently with the pre-clinical curriculum, and offers surgeryspecific lecture topics and skill sessions relevant to the underclassmen's studies.

\section{GSS Faculty Members}

\author{
Renee M. Tholey, MD, FACS \\ Charles J. Yeo, MD, FACS \\ Gerald Isenberg, MD, FACS \\ Michael Pucci, MD, FACS
}

There are also events that are available to all students. The GSS runs a quarterly journal club, which is led by a surgeon at Jefferson in the field that is currently being studied by the second-year medical students; typically, one "classic" article from the literature is discussed and contrasted with a contemporary article. The basic anatomy and physiology are presented by a first- and second-year medical student, and the findings of the papers are reviewed by a third-year medical student. Many surgeons take this time to not only educate the students in critical review of the findings of papers, but also the underlying statistics that were used. The Philadelphia Surgical Symposium is the GSS's signature event and is run in the spring of each year. Students from all medical schools in the Philadelphia region (six schools in total) are invited, and it is intended to be an informative opportunity for medical students interested in surgery. There is an associated regional medical student research poster session and competition during the event, complemented by presentations from a faculty member from each school, ranging in topics from clinical experiences, to advocating for a particular field of surgery, to hot topics in research. The event concludes with a two-hour networking session, either on site or at a nearby venue.

The GSS was presented at the AAMC's Learn, Serve, Lead 2017 conference as a model for an effective medical student interest group. This journal, the GSR, is written, compiled, and curated by SKMC students through the invaluable help and planning of the GSS members, and stands not only as a testament to the involvement and hard work of the GSS, but also of the student body as a whole.

-Tyler M. Bauer, Class of 2020

Senior Editor

\section{GSS Board Members}

\author{
Alex Rowan, MS4 \\ Amanda Nemecz, MS4 \\ Annalise Penikis, MS4 \\ Gabe Cambronero, MS4 \\ Zach Plona, MS4 \\ J.J. Newland, MS4 \\ Brandon Nussenblatt, MS4 \\ Elwin Tham, MS4 \\ J.Y. Leong, MS4 \\ Harold Salmons, MS3 \\ Karim Hafazalla, MS3 \\ Victor Hsue, MS3 \\ Samantha Savitch, MS2 \\ Emily Papai, MS2
}




\section{THE GIBBON SURGICAL SOCIETY}
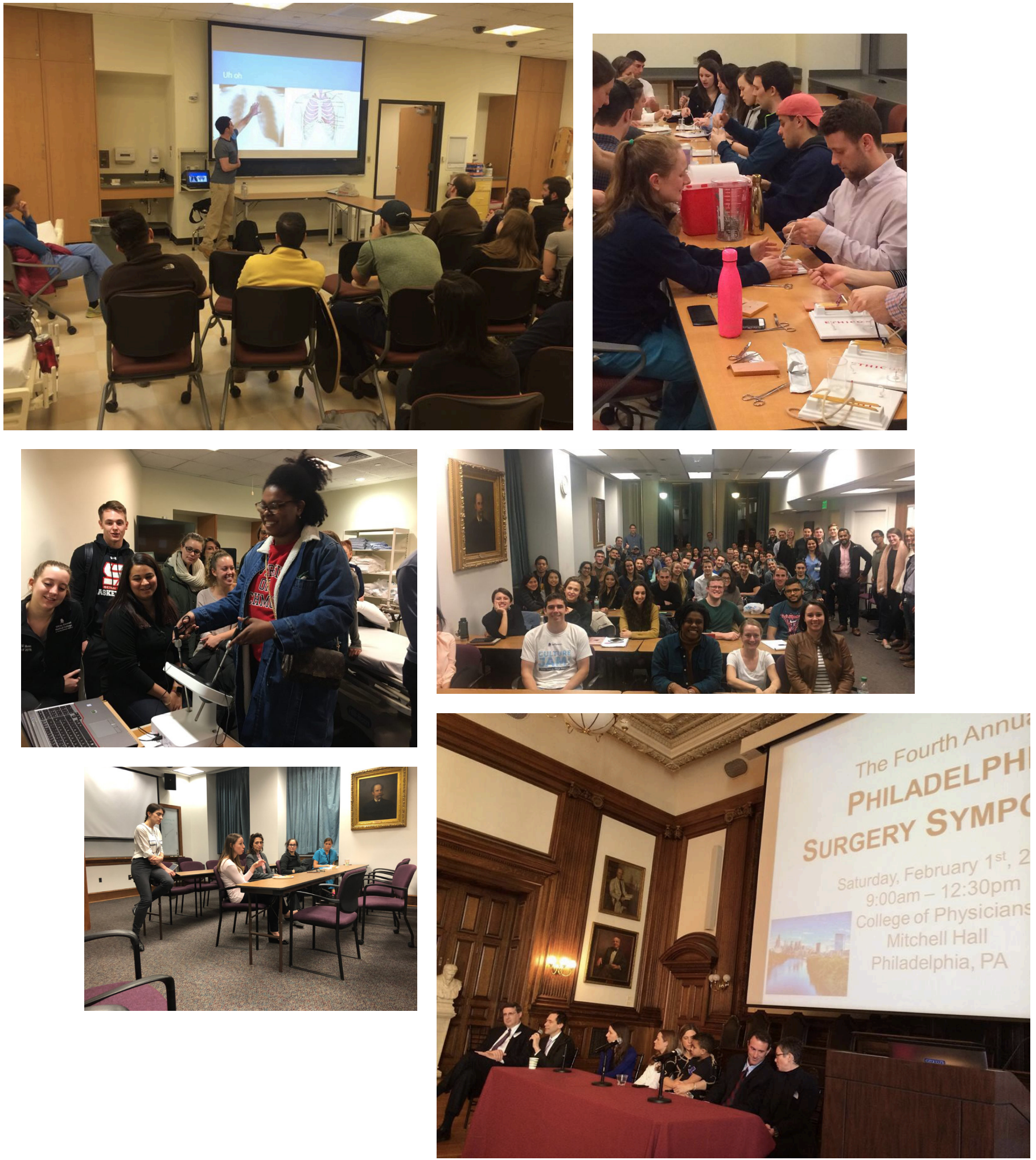


\section{Faculty Advisors}

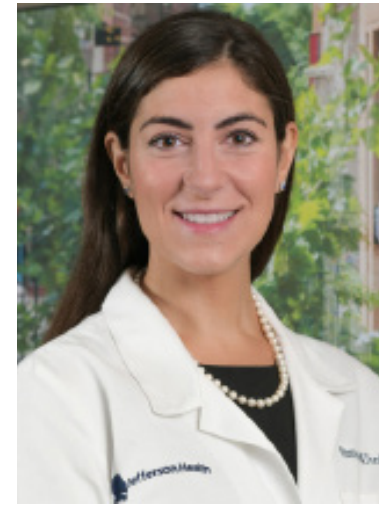

Renee M. Tholey, MD, FACS

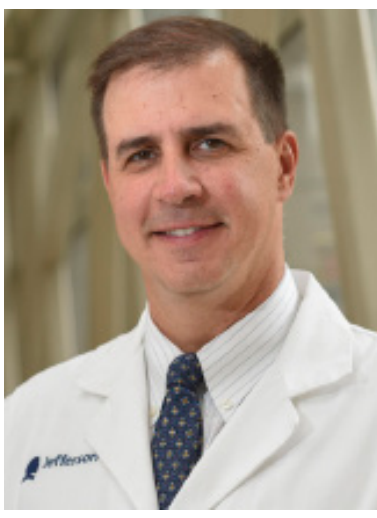

Scott W. Cowan, MD, FACS

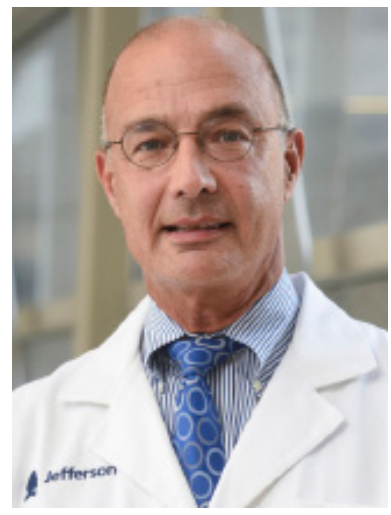

Charles J. Yeo, MD, FACS

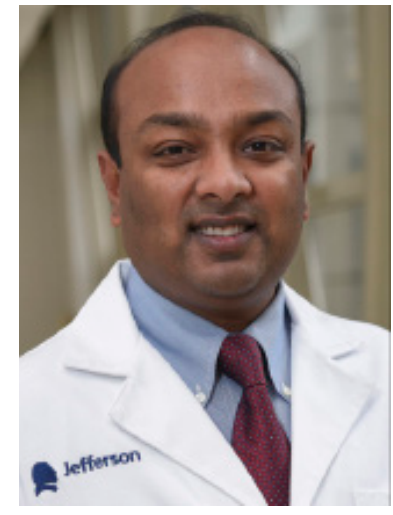

Harish Lavu, MD, FACS

\section{Editorial Team}

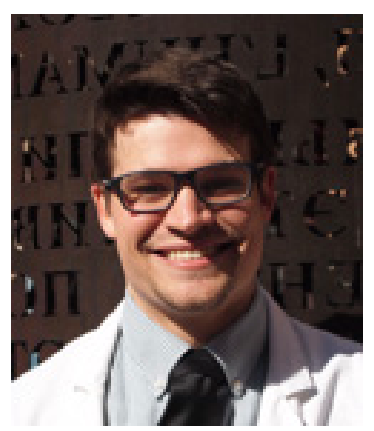

Tyler M. Bauer, MS4

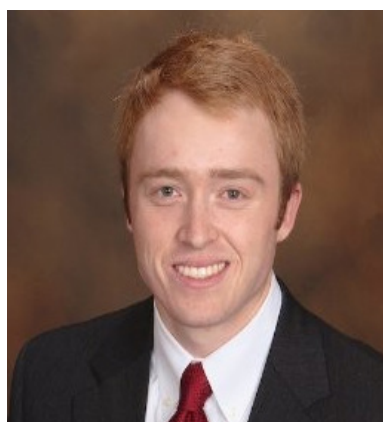

Harold I. Salmons, MS3

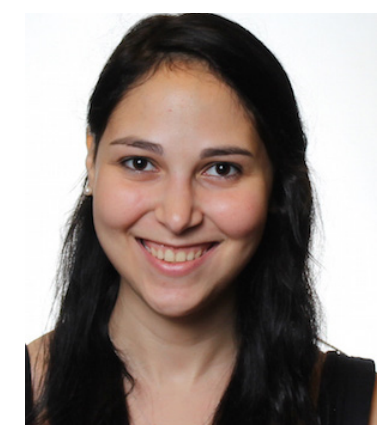

Samantha L. Savitch, MS2

\section{REVIEWERS}

Melissa A. Lazar, MD, FACS Jonathan R. Brody, PhD Theresa P. Yeo, PhD, MPH Charles J. Yeo, MD, FACS Scott W. Cowan, MD, FACS Harish Lavu, MD, FACS Renee M. Tholey, MD, FACS

\section{GUEST WRITERS}

Carrie D. Walsh, MS3

Nicholas Siena, MS3

Kevin Xie, MS2

ACKNOWLEDGEMENTS

Kelly M. Austin Sherry Weitz 


\section{CHARLES J. YEO, MD, FACS}

Dr. Charles J. Yeo was born in East Orange, New Jersey, and attended Spring Valley Senior High School in Spring Valley, New York. He received his undergraduate degree from Princeton University in 1975, summa cum laude, with an A.B. in Biochemistry. Dr. Yeo graduated in 1979 from the Johns Hopkins University School of Medicine, being awarded the Upjohn Achievement Award, and was elected to Alpha Omega Alpha and Phi Beta Kappa. He went on to complete his residency in General Surgery and a fellowship in advanced Gl and vascular surgery at the Johns Hopkins Hospital.

Dr. Yeo joined the faculty of the Johns Hopkins University as an Instructor and Assistant Chief of Service in the Department of Surgery in 1985, and rose to the rank of Professor of Surgery in 1996. Dr. Yeo directed the Pancreatic Cancer Interdisciplinary Working Group at Johns Hopkins and served as the Surgical Clerkship Coordinator and Surgical Curriculum Consultant. In 2001, Dr. Yeo received the Alumni Association Excellence in Teaching Award from the Johns Hopkins University School of Medicine. In 2002, Dr. Yeo was named to an endowed chair at Johns Hopkins, becoming the inaugural John L. Cameron, MD Professor for Alimentary Tract Diseases.

On October 1, 2005 Dr. Yeo was named the 8th Samuel D. Gross Professor of Surgery, and he assumed the chairmanship of the Department of Surgery at Sidney
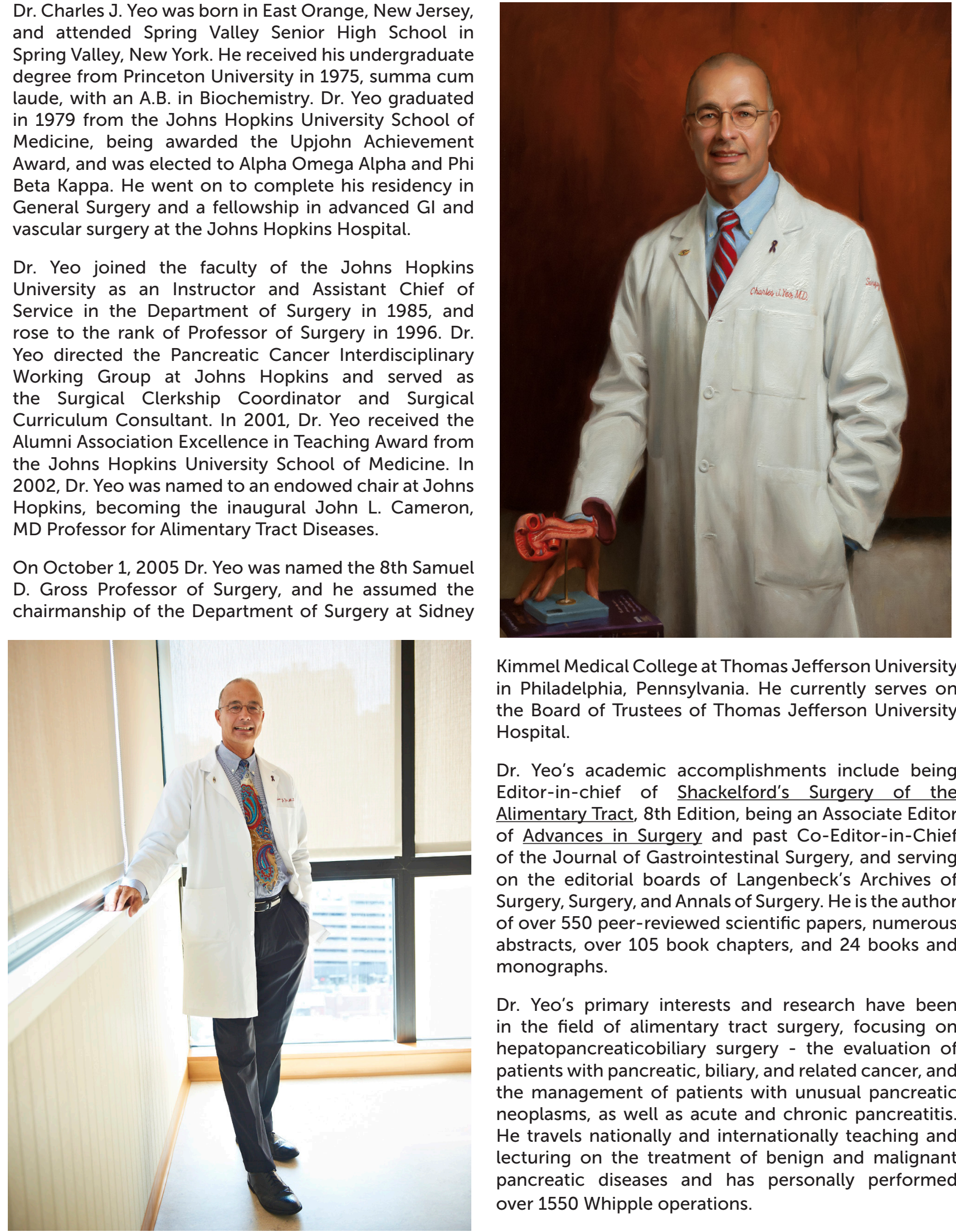

Kimmel Medical College at Thomas Jefferson University in Philadelphia, Pennsylvania. He currently serves on the Board of Trustees of Thomas Jefferson University Hospital.

Dr. Yeo's academic accomplishments include being Editor-in-chief of Shackelford's Surgery of the Alimentary Tract, 8th Edition, being an Associate Editor of Advances in Surgery and past Co-Editor-in-Chief of the Journal of Gastrointestinal Surgery, and serving on the editorial boards of Langenbeck's Archives of Surgery, Surgery, and Annals of Surgery. He is the author of over 550 peer-reviewed scientific papers, numerous abstracts, over 105 book chapters, and 24 books and monographs.

Dr. Yeo's primary interests and research have been in the field of alimentary tract surgery, focusing on hepatopancreaticobiliary surgery - the evaluation of patients with pancreatic, biliary, and related cancer, and the management of patients with unusual pancreatic neoplasms, as well as acute and chronic pancreatitis. He travels nationally and internationally teaching and lecturing on the treatment of benign and malignant pancreatic diseases and has personally performed over 1550 Whipple operations. 
To learn more about supporting pancreatic cancer research or clinical care at Thomas Jefferson University Hospital, contact Kelly Austin, Director of Development, at 215-955-6383 or Kelly.Austin@jefferson.edu. 